\title{
Tracking the dynamics of paddy rice planting area in 1986-2010 through time series Landsat images and phenology-based algorithms
}

\author{
Jinwei Dong a,b ${ }^{\text {a }}$ Xiangming Xiao ${ }^{\text {a,b,c,* }}$, Weili Kou ${ }^{\text {a,b,d }}$, Yuanwei Qin ${ }^{\text {a,b }}$, Geli Zhang a,b ${ }^{\text {Li Li }}{ }^{\text {a,b,e }}$, Cui Jin ${ }^{\text {a,b }}$, \\ Yuting Zhou ${ }^{\mathrm{a}, \mathrm{b}}$, Jie Wang ${ }^{\mathrm{a}, \mathrm{b}}$, Chandrashekhar Biradar ${ }^{\mathrm{f}}$, Jiyuan Liu ${ }^{\mathrm{g}}$, Berrien Moore III ${ }^{\mathrm{h}}$ \\ a Department of Microbiology and Plant Biology, University of Oklahoma, Norman, OK 73019, USA \\ b Center for Spatial Analysis, University of Oklahoma, Norman, OK 73019, USA \\ c Institute of Biodiversity Science, Fudan University, Shanghai 200433, China \\ d School of Computer Science and Information, Southwest Forestry University, Kunming, 650224 China \\ e College of Information \& Electrical Engineering, China Agricultural University, Beijing 100083, China \\ ${ }^{\mathrm{f}}$ International Center for Agricultural Research in Dry Areas, Amman 11195, Jordan \\ g Institute of Geographic Sciences and Natural Resources Research, Chinese Academy of Sciences, Beijing 100101, China \\ ${ }^{\mathrm{h}}$ College of Atmospheric and Geographic Sciences, University of Oklahoma, Norman, OK 73019, USA
}

\section{A R T I C L E I N F O}

\section{Article history:}

Received 20 April 2014

Received in revised form 6 January 2015

Accepted 10 January 2015

Available online 28 January 2015

\section{Keywords:}

Paddy rice

Landsat-RICE

Phenology

Land use change

Northeast China

\begin{abstract}
A B S T R A C T
Agricultural land use change substantially affects climate, water, ecosystems, biodiversity, and human welfare. In recent decades, due to increasing population and food demand and the backdrop of global warming, croplands have been expanding into higher latitude regions. One such hotspot is paddy rice expansion in northeast China. However, there are no maps available for documenting the spatial and temporal patterns of continuous paddy rice expansion. In this study, we developed an automated, Landsat-based paddy rice mapping (LandsatRICE) system that uses time series Landsat images and a phenology-based algorithm based on the unique spectral characteristics of paddy rice during the flooding/transplanting phase. As a pilot study, we analyzed all the available Landsat images from 1986 to 2010 (498 scenes) in one tile (path/row 113/27) of northeast China, which tracked paddy rice expansion in epochs with five-year increments (1986-1990, 1991-1995, 1996-2000, 2001-2005, and 2006-2010). Several maps of land cover types (barren land and built-up land; evergreen, deciduous and sparse vegetation types; and water-related land cover types such as permanent water body, mixed pixels of water and vegetation, spring flooded wetlands and summer flooded land) were generated as masks. Air temperature was used to define phenology timing and crop calendar, which were then used to select Landsat images in the phenology-based algorithms for paddy rice and masks. The resultant maps of paddy rice in the five epochs were evaluated using validation samples from multiple sources, and the overall accuracies and Kappa coefficients ranged from 84 to $95 \%$ and $0.6-0.9$, respectively. The paddy rice area in the study area substantially increased from 1986 to 2010, particularly after the 1990s. This study demonstrates the potential of the Landsat-RICE system and time series Landsat images for tracking agricultural land use changes at 30-m resolution in the temperate zone with single crop cultivation.
\end{abstract}

(c) 2015 Elsevier Inc. All rights reserved.

\section{Introduction}

As a fundamental component of global environmental change and sustainability research (Turner, Lambin, \& Reenberg, 2007), land cover and land use change (LCLUC) greatly affects the carbon and water cycles (West et al., 2010), biodiversity (Gibson et al., 2011), and human welfare (Foley et al., 2005). Many areas in the world had expansion of crop and pastoral lands from natural ecosystems in the past decades (Lambin \& Meyfroidt, 2011; Turner et al., 2007). Maintaining agricultural land area is a critical challenge for global food security (Thenkabail,

* Corresponding author at: 101 David L. Boren Blvd., Norman, OK 73019, USA. Tel.: + 1 4053258941.

E-mail address: xiangming.xiao@ou.edu (X. Xiao).
2009), particularly in China with a large and increasing population (Tao, Yokozawa, Liu, \& Zhang, 2009). In some regions of China, large areas of cropland were either converted to built-up land due to urbanization or returned to forest and grassland due to ecological restoration projects (Liu et al., 2014). In high latitudinal areas, agricultural expansion is a new trend due to climatic warming (Dong, Liu, Tao, Xu, \& Wang, 2009; Dong, Liu, Yan, Tao, \& Kuang, 2011; Liu et al., 2014). Northeast China has been undergoing an especially rapid expansion of paddy rice in past decades that has yielded more grain production, resulted in the northeastward shift of the crop production center in China (Cheng, Wang, Guo, Zhao, \& Huang, 2012), and had remarkable impacts on the carbon cycle and water management (Wang et al., 2010). The cropland reclamation that occurred in northeast China featured the conversion of wetland and upland cropland to paddy rice 
fields (Wang et al., 2011). High soil organic carbon, long crop seasons and high rice biomass in northern China enhanced methane emission in paddies (Zhang, Wang, Su, \& Li, 2011). Therefore, the amount of methane emissions from paddy rice fields needs to be quantified in northeast China. In addition, paddy rice expansion has also raised a series of environmental problems, including water resource shortage (Tao, Hayashi, Zhang, Sakamoto, \& Yokozawa, 2008), land degradation and biodiversity loss (Yang, Yan, \& Zhu, 2011).

Several global land cover products include a layer of croplands in China, for example, the MCD12Q1 from the Moderate-resolution Imaging Spectroradiometer (MODIS) (Friedl et al., 2002, 2010), the GlobCover from the MEdium Resolution Imaging Spectrometer (MERIS) (Arino et al., 2008), and the Finer Resolution Observation and Monitoring-Global Land Cover (FROM-GLC) from Landsat (Gong et al., 2013). All of these efforts were based on the spectral features of land cover types in certain phases using supervised or unsupervised classification approaches. Due to different data resolutions, classification schemes, algorithms, research aims, and validation intensities, these products differ to various degrees (Dong et al., 2012; Fritz, See, \& Rembold, 2010; Waser \& Schwarz, 2006). The algorithms of these land cover datasets rely on image statistics, training sample collection and/or human visual interpretation. The image statistics are imagedependent, therefore, the repeatability of these algorithms is low. In these land cover datasets, cropland was typically considered as one land cover category that contains different crop species, and there were large discrepancies of cropland distribution among the various datasets (Wu, Shibasaki, Yang, Zhou, \& Tang, 2008). More specific information on crop type, e.g., paddy rice, is still limited in these existing land cover products.

The phenology-based approach, based on a time series of spectral reflectance or vegetation indices at individual pixels, is an alternate way to identify and map land cover types. Several studies adopted phenological metrics (e.g., starting date, ending date) to map land cover types including soybean and corn (Zhong, Gong, \& Biging, 2014). Spectral matching techniques (SMT) have also been used to map land cover and irrigated areas (Thenkabail et al., 2009; Thenkaball, GangadharaRao, Biggs, Krishna, \& Turral, 2007). Other studies evaluated spectral properties of various phenological phases, carefully selected one or two unique phases and associated it with spectral signature to identify and map land cover types (Dong et al., 2013; Xiao et al., 2005, 2006). Specifically, a phenology-based approach was used to develop an automated paddy rice mapping algorithm (Xiao et al., 2002), as paddy rice fields have a phase of flooding and open-canopy (after rice transplanting) when a mixture of surface water and rice crops exists. This phenology feature has been used for mapping paddy rice in Southern China and Southeast Asia with MODIS data (Xiao, Boles, et al., 2005; Xiao et al., 2006).

The freely available Landsat archive data that have existed for the past forty years (1972 to present) offer unprecedented opportunities to document historical land cover change with a longer range than that of MODIS. The Landsat Thematic Mapper (TM) sensor, Enhanced Thematic Mapper Plus (ETM+) sensor, and Operational Land Imager (OLI) have the same spatial resolution and continuous temporal coverage. Several regional scale studies have used 30-m Landsat imagery to quantify changes in forest areas. For example, Hansen et al. (2013) mapped global forest extent and annual loss and gain from 2000 to 2012, and another study reported forest disturbance trends in the United States using Landsat time series data and the Vegetation Change Tracker (VCT) algorithm (Huang et al., 2010; Masek et al., 2013). Based on the visual interpretation and digitalization of individual Landsat images, multi-temporal land cover maps in China from the 1980s to 2010 with 5-year intervals have been generated in the China National Land Cover Datasets (NLCD China), including two categories of cropland: paddy cropland (mainly paddy rice) and upland cropland (Liu et al., 2005, 2014). However, the NLCD work was timeconsuming and labor-intensive, and the accuracy was largely dependent on the experiences of interpreters and image selection (e.g., rice and wheat could have similar spectral features in some periods).
The application of time series Landsat images to quantifying longterm agricultural land use change at the regional scale is very challenging due to the variability and complexity of the spectral and texture signatures from different crop types. Our goal is to develop an automated time series Landsat- and phenology-based system and use it to map paddy rice fields for the last three decades. We plan to use all the Landsat images available in the U.S. Geological Survey Center for Earth Resources Observation and Science (USGS EROS) archive for one path/row. This process requires practical approaches for atmospheric correction and the identification and exclusion of bad-quality observations including clouds, cloud shadows, snow, and missing data in $\mathrm{ETM}+$ due to scan line corrector off (SLC-off). The Landsat Ecosystem Disturbance Adaptive Processing System (LEDAPS) (Masek et al., 2006) has been widely used for the time series Landsat image processing (Huang et al., 2009; Thomas et al., 2011). Previous studies indicated that cloud cover and their shadows have non-ignorable effects (Asner, 2001; Lindquist, Hansen, Roy, \& Justice, 2008) and several algorithms have been developed to detect them (Goodwin, Collett, Denham, Flood, \& Tindall, 2013; Simpson, Jin, \& Stitt, 2000; Zhu \& Woodcock, 2012). For example, Zhu and Woodcock (2012) developed an operational routine Fmask to detect clouds and cloud shadows. The snow detection algorithm has been developed and widely applied (Hall, Riggs, \& Salomonson, 1995). SLC-off gaps can be acquired from the metadata. It will be valuable to build the time series datasets with all of the good-quality observations and evaluate its potential to map paddy rice, which would contribute to improving land cover mapping and change detection capability.

The objective of this study is three-fold: (1) to develop a Landsatand phenology-based paddy rice mapping system (Landsat-RICE) to process time series Landsat data including vegetation index calculation, exclusion of bad-quality observations (cloud, cloud shadow, snow, and SLC-off gaps), subsetting and stacking of time series data, and phenology-based paddy rice mapping; (2) to improve and evaluate the feasibility and accuracy of pixel- and phenology-based algorithms in mapping paddy rice using all of the available Landsat images and air temperature-based phenology timing definitions; and (3) to provide satellite-based evidence for documenting paddy rice expansion in northeast China over the past three decades at such five-year intervals as the late 1980s (1986-1990), early 1990s (1991-1995), late 1990s (1996-2000), early 2000s (2001-2005), and late 2000s (2006-2010).

\section{Materials and methods}

In this study, we developed a Landsat data processing system for mapping paddy rice over decades, which is composed of two modules: (1) the image data preprocessing module (see Section 2.2 for details) and (2) pixel- and phenology-based paddy rice mapping module (Section 2.3). Fig. S1 shows the schematic diagram of the Landsat- and phenology-based paddy rice mapping system (LandsatRICE). As a pilot and methodological study, we selected one Landsat scene (path/row 113/27) in northeast China as the study area. Using the resultant paddy rice maps over decades, we quantified the paddy rice expansion pattern and process from 1986 to 2010.

\subsection{Study area}

Our study area covers the border area of China and Russia between $133.153-136.125^{\circ} \mathrm{E}$ and $46.530-48.371^{\circ} \mathrm{N}$, which is part of the Sanjiang Plain. The western part of the study area is largely flat and is dominated by paddy rice (Fig. 1). The climate of the study area is the middle temperate and humid zone with monsoons. The annual mean temperature is approximately $2.5^{\circ} \mathrm{C}$, with the lowest temperature occurring in January at around $-20^{\circ} \mathrm{C}$, and the highest temperature in July at $22^{\circ} \mathrm{C}$. The annual accumulated temperature above $10^{\circ} \mathrm{C}$ is over $2400{ }^{\circ} \mathrm{C}$. day. The annual precipitation is approximately $500 \mathrm{~mm}$. There are several large rivers in the study area, including the Heilongjiang River, Wusuli River, and Naoli 

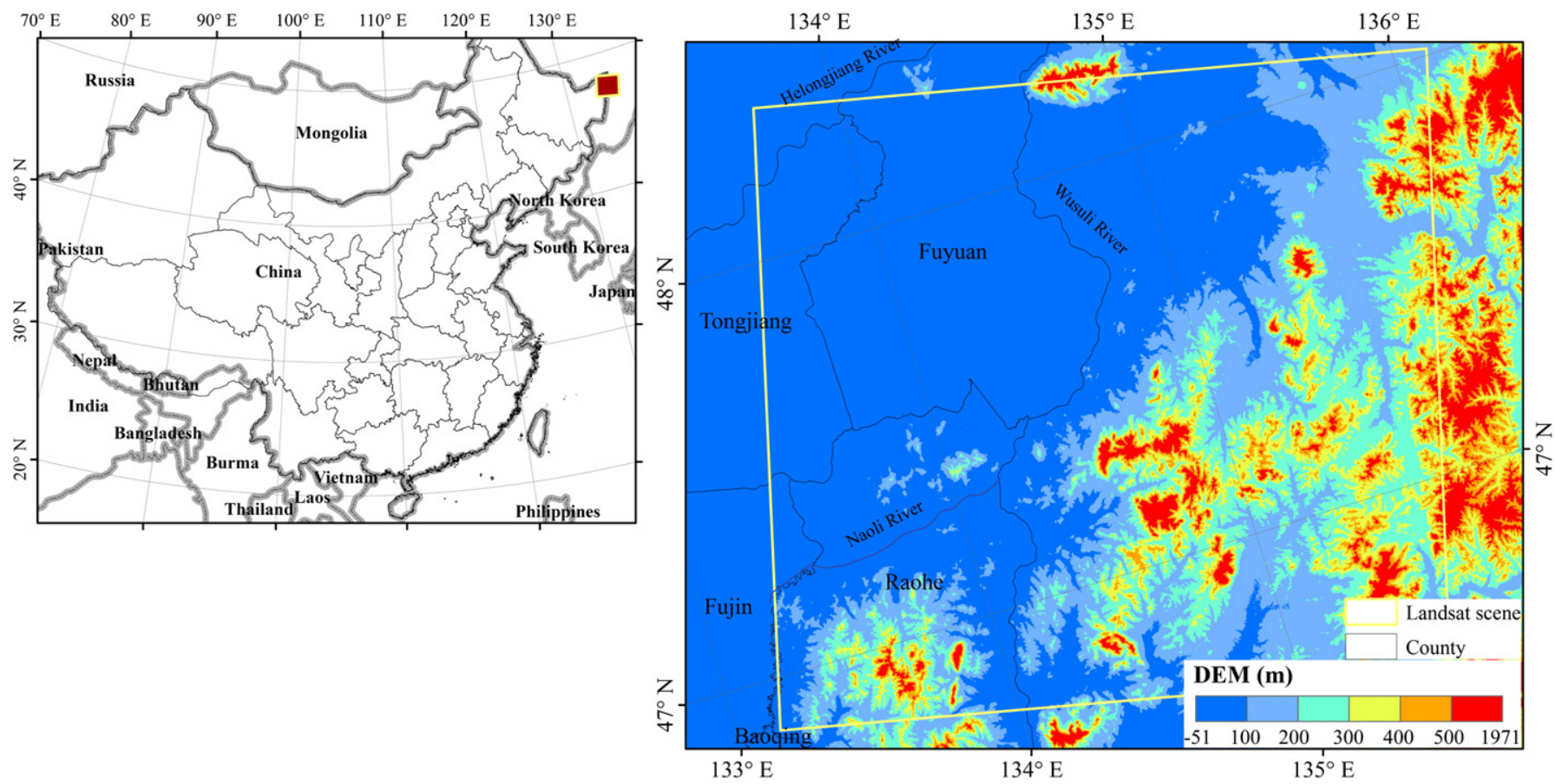

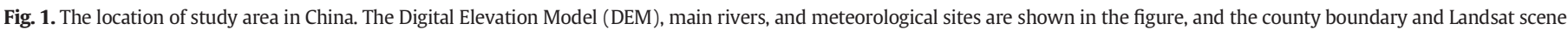
extent (path/row 113/27) are highlighted.

River, which provide rich water resources for paddy rice planting. The soil is suitable for cropping with high fertility, e.g., Aquepts soil and Cryalfs soil.

The Chinese portion of the study area includes two counties (Fuyuan and Raohe), and both have large areas of croplands, such as paddy rice, corn, and soybean fields (Fig. 1). The cropland area per capita in the study area is much higher than the national average level. The planting areas of paddy rice and corn increased rapidly, which led to a loss in wetlands (Liu, Zhang, Li, Lu, \& Yang, 2004; Wang et al., 2011; Zhang et al., 2009). Liu et al. (2004) found that $73.6 \%$ of the wetlands in the northeastern part of Heilongjiang Province were lost due to agricultural development from 1950 to 2000, while Wang et al. (2011) also found that the wetlands in the Sanjiang Plain have decreased by $77 \%$ from 1954 to 2005. At the same time, cropland was found to have increased dramatically (Zhang et al., 2009).

\subsection{Time series Landsat image preprocessing}

We developed the Landsat data preprocessing protocol to process hundreds of Landsat images over time including atmospheric correction, bad-quality observation detection of clouds, cloud shadows, snow and SLC-off pixels, data quality labeling, image co-registration, and data subsetting and stacking (clipping data to a common geographic range and assembling them into a time series stack) (Fig. 2). All of these preprocessing procedures made use of the multiple-core and Linux-based servers.

\subsubsection{Image data acquisition}

The free accessibility of the U.S. Geological Survey Center for Earth Resources Observation and Science (USGS/EROS) enabled usage of all of the available Landsat archive data for temporal and phenology analysis. We downloaded all the available Landsat TM and ETM + images (path/row 113/27) from 1986 to 2010 from the USGS/EROS, including the standard Level 1 Terrain-corrected (L1T) images and other images with different processing levels. Finally, we had a total of 498 images for the scene (path/row 113/27), which provided good temporal coverage (Fig. 3) with an average of 1.66 images per month from 1986 to
2010 (Fig. S2). Fig. 3 shows that the period with the most Landsat images were from 2000 to 2004 with Landsat 5 TM and ETM +. The early 1990s' epoch had the fewest images. The seasonal distribution of the Landsat images showed that the Landsat data in the four seasons were generally even, with slightly larger amounts in the summer and autumn. Landsat images in the winter season had snow cover in most pixels.

There are three categories of Landsat products: the L1T, Level 1 Systematically Corrected (L1G), and Systematically Terrain Corrected (L1Gt) (NASA Goddard Space Flight Center, 2011). All of the radiometric and geometric corrections have been conducted in all of the three categories of products. While the overall geometric fidelity has also been fitted using ground control points and a digital elevation model for L1T; a Digital Elevation Model (DEM) is employed for topographic accuracy of L1Gt; no terrain correction is applied in L1G products, and the geometric accuracy of the systematically corrected product should be within $250 \mathrm{~m}$ (1 sigma) for low-relief areas at sea level (NASA Goddard Space Flight Center, 2011). We did not conduct further terrain correction on the L1G data as it was beyond the aims of this study, but we excluded seven mis-registration Landsat 5 TM images (1986100, 1986276, 1987279, 1988250, 1988282, 1990127, and 1990303), by using the image matching verification function in the Automated Registration and Orthorectification Package (AROP) (Gao, Masek, \& Wolfe, 2009), which is a registration and orthorectification package for processing Landsat and Landsat-like data.

\subsubsection{Atmospheric correction}

Atmospheric correction was conducted to generate surface reflectance by using the LEDAPS software (Masek et al., 2006), which uses the MODIS 6S radiative transfer approach to retrieve surface reflectance (Masek et al., 2006; Vermote et al., 1997). The LEDAPS includes the calibration from at-sensor radiance (digital number, DN) to topof-atmosphere (TOA) reflectance and the atmospheric correction from TOA reflectance to surface reflectance using ancillary National Centers for Environmental Prediction (NCEP) water vapor data and Total Ozone Mapping Spectrometer (TOMS) ozone data. 

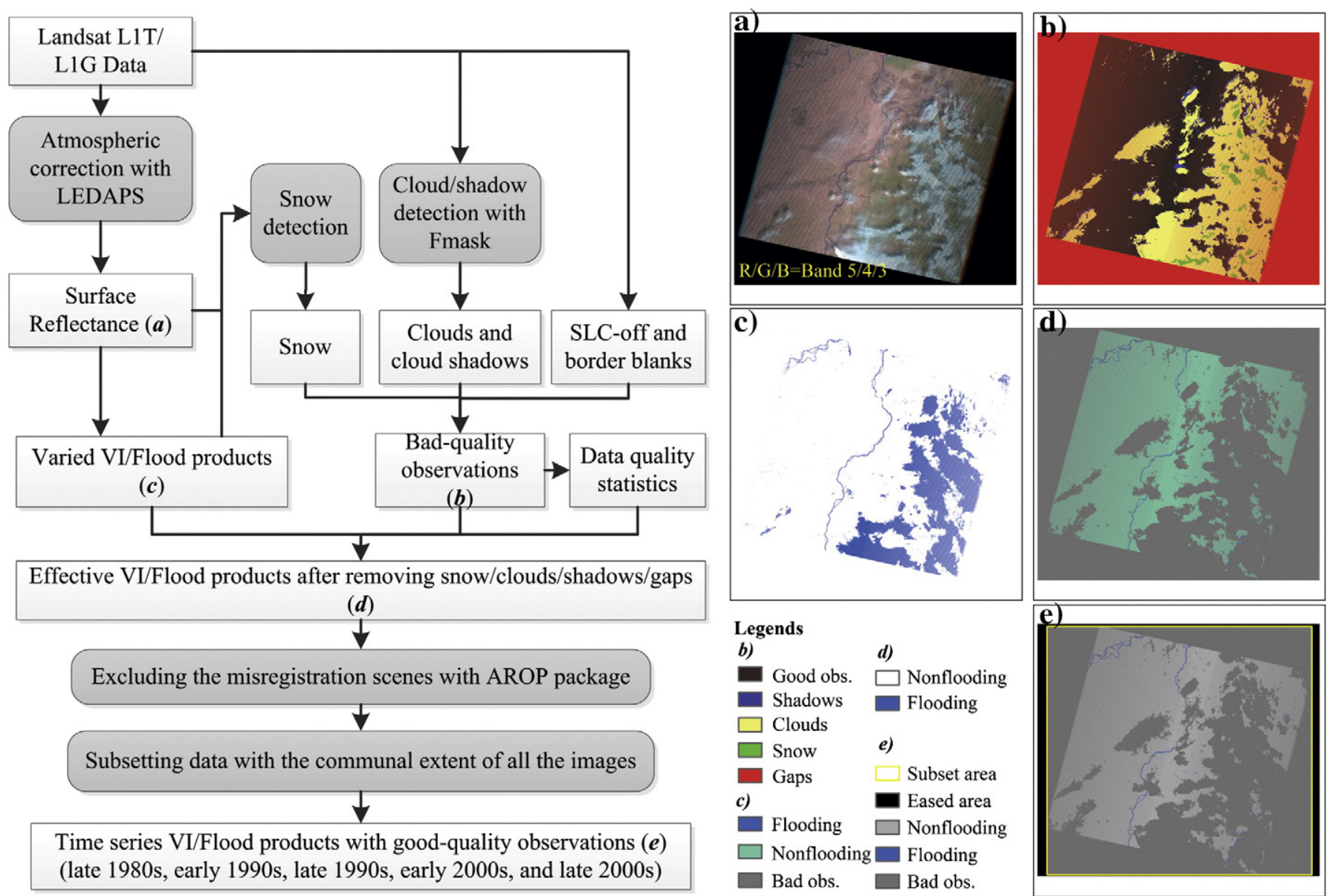

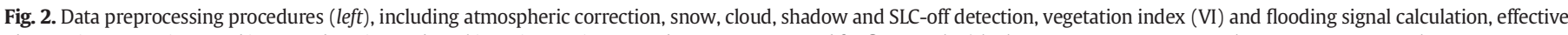

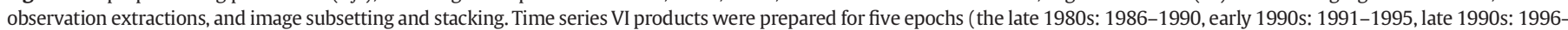

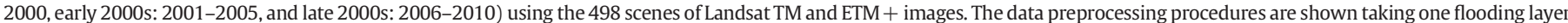

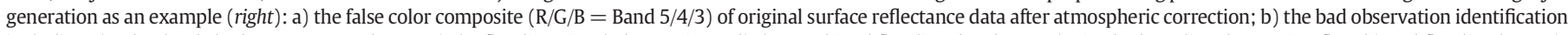

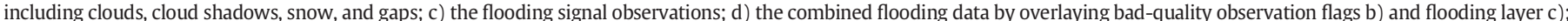

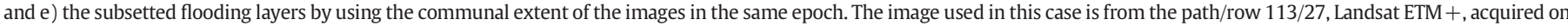
the 105th day of 2008. The sequence numbers (a-e) in the left diagram are corresponding with that of the right figures.

\subsubsection{Calculation of vegetation indices}

We calculated three vegetation indices: Normalized Difference Vegetation Index (NDVI) (Tucker, 1979), Enhanced Vegetation Index (EVI) (Huete, Liu, Batchily, \& vanLeeuwen, 1997; Huete et al., 2002), and Land Surface Water Index (LSWI) (Xiao, Zhang, Hollinger, Aber, \& Moore, 2005; Xiao et al., 2004). These indices have been widely used in the studies of vegetation canopy, biomass, water content, and phenology. We also calculated the Normalized Difference Snow Index (NDSI), which was used for snow detection (Hall et al., 1995). These spectral indices were calculated using the Landsat surface reflectance based on the following equations and spectral bands:

$\mathrm{NDVI}=\frac{\rho_{\text {NIR }}-\rho_{\text {red }}}{\rho_{\text {NIR }}+\rho_{\text {red }}}$

$\mathrm{EVI}=2.5 \times \frac{\rho_{\text {NIR }}-\rho_{\text {red }}}{\rho_{\text {NIR }}+6 \times \rho_{\text {red }}-7.5 \times \rho_{\text {blue }}+1}$

$\mathrm{LSWI}=\frac{\rho_{\text {NIR }}-\rho_{\text {SWIR }}}{\rho_{\text {NIR }}+\rho_{\text {SWIR }}}$

$\mathrm{NDSI}=\frac{\rho_{\text {green }}-\rho_{\text {SWIR }}}{\rho_{\text {green }}+\rho_{\text {SWIR }}}$ where $\rho_{\text {blue }}, \rho_{\text {green }}, \rho_{\text {red }}, \rho_{\text {NIR }}$, and $\rho_{\text {SWIR }}$ are the surface reflectance values of Band 1 (blue, 0.45-0.52 mm), Band 2 (green, 0.53-0.61 mm), Band 3 (red, 0.63-0.69 mm), Band 4 (near-infrared, NIR for short hereafter, $0.76-0.90 \mathrm{~mm}$ ) and Band 5 (shortwave-infrared, 1.55-1.75 mm) in the Landsat TM/ETM + sensors.

We further calculated the (1) difference between LSWI and NDVI (LSWI - NDVI) and (2) difference between LSWI and EVI (LSWI - EVI) for each of Landsat images. The resultant difference maps provided additional information on the mixture (mixing ratio) of water, soils, and plants within a pixel.

\subsubsection{Bad-quality observations in Landsat images}

Bad observations were identified, including clouds, cloud shadows, SLC-off gaps, and snow cover. Fig. 2 shows detailed data preprocessing procedures for exclusion of these bad-quality observations. After these preprocessing procedures, the vegetation index data were clipped according to a common geographic extent and assembled into a time series dataset ready for use.

2.2.4.1. ETM + SLC-off pixels. The Landsat $7 \mathrm{ETM}+$ came into operation in 1999 as the successor of TM; however, the scan-line corrector (SLC) of ETM + failed permanently on May 31st, 2003, which caused approximately $22 \%$ of the pixels to be missing from an image (Arvidson, 
a)
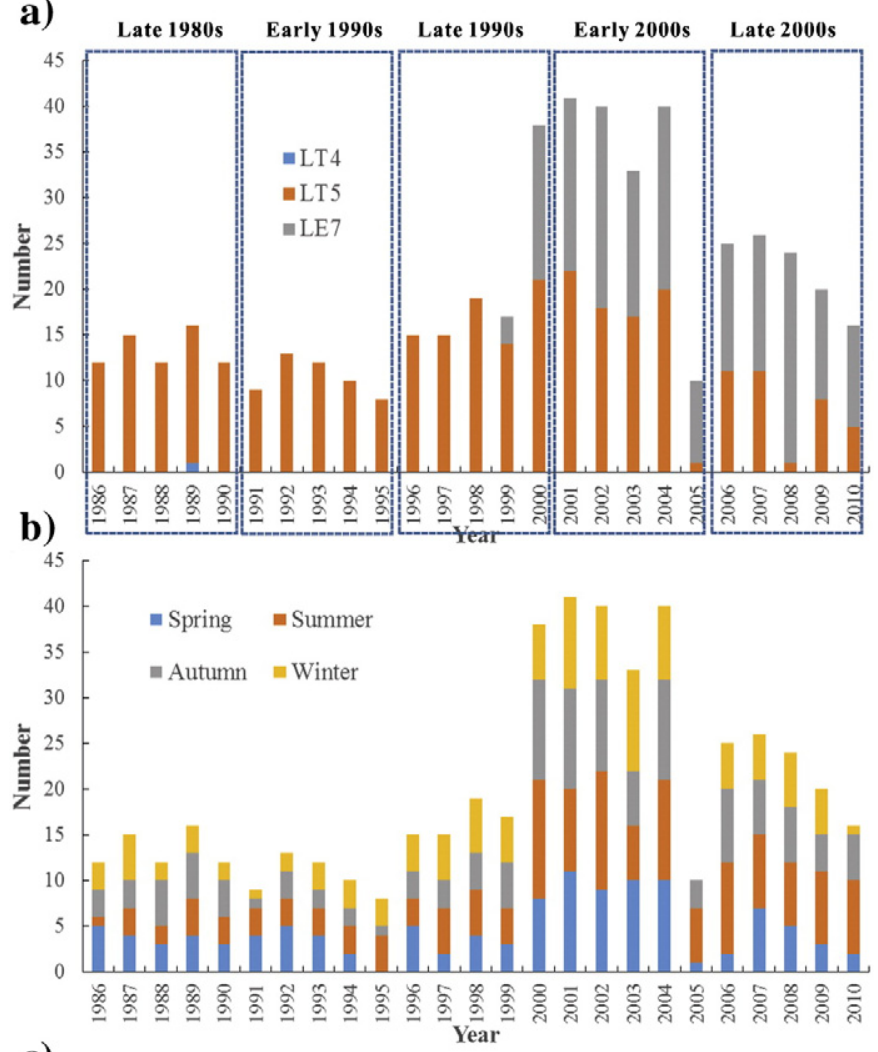

c)

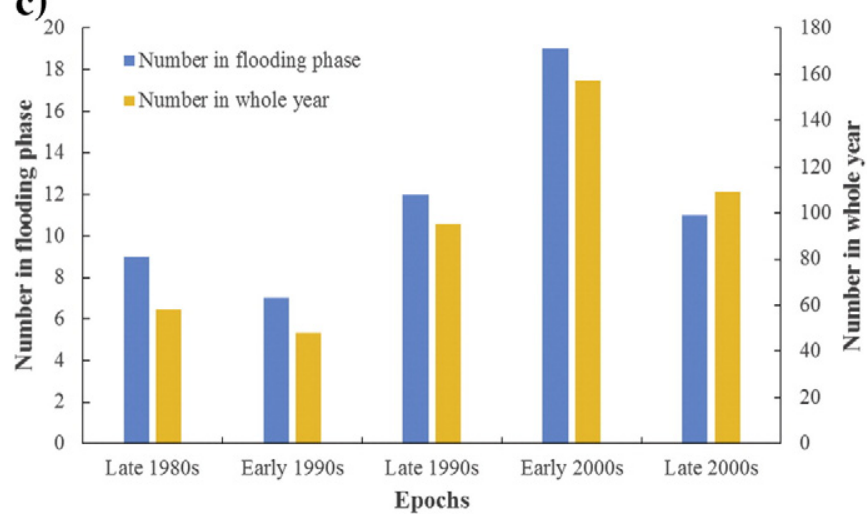

Fig. 3. The annual distribution of Landsat imagery by a) sensors (Landsat TM 4, Landsat TM 5, and Landsat ETM +) and b) seasons (spring, summer, autumn, and winter) in the study area for the scene (path/row 113/27) from 1986 to 2010. c) The image numbers in the flooding and transplanting phase and whole year for the five epochs.

Goward, Gasch, \& Williams, 2006). The SLC-off was most obvious in the edge area of an image and gradually diminishes toward the center of the image. We excluded the SLC-off gaps for ETM + images according to their metadata.

2.2.4.2. Clouds and cloud shadows. Cloud and cloud shadow detection is essential for optical remote sensing data processing. We used the Fmask routine (Zhu \& Woodcock, 2012) to detect the clouds and cloud shadows in an image, which first identifies potential cloud pixels based on cloud physical properties, then detects cloud shadows through its darkening effects in the NIR band and a flood-fill transformation method, and finally, matches clouds and cloud shadows to generate the map of cloud and cloud shadow. Although a recent study found that temporal information from time series images can improve the detection capability of cloud and cloud shadow (Goodwin et al., 2013), Fmask has the advantage of processing a large amount of images in a more computationally efficient way.
2.2.4.3. Snow cover. Snow cover in the study region was another issue for land cover mapping and needed to be eliminated as well (Xiao, Boles, et al., 2005). In this study, we used the NDSI index and NIR spectral band to identify snow cover with the thresholds NDSI $>0.40$ and NIR $>0.11$ (Hall et al., 1995). The snow cover was extracted from each of the Landsat images. Those pixels identified as snow cover were also excluded from the identification of paddy rice fields, together with clouds and cloud shadows.

2.2.4.4. Statistical analysis of good-quality observations of time series Landsat images. Because good quality observations for each month of every year were unavailable (Fig. S2), it was necessary to combine images from multiple years (epochs) for the paddy rice analysis. Fig. $3 c$ shows the data availability status for the whole year and the flooding/transplanting phase in each epoch. Good observation numbers in individual pixels varied over space. We calculated pixel-based statistics for good observation numbers, excluding clouds, cloud shadows, snow, and SLC-off gaps, over the flooding and transplanting phase (Fig. 4a-e) and the whole year (Fig. 4f-j) for the five epochs. The maximum number of good-quality observations within a pixel during the flooding and transplanting phase was 9 in the late 1980s, 7 in the early 1990s, 12 in the late 1990s, 19 in the early 2000s, and 11 in the late 2000s (Fig. 3c). In the epoch of the early 2000s, $99 \%$ of pixels had over seven good-quality observations in the flood/transplanting phase. In the epochs of late 1990 s, late 1980 s and late 2000 s, $84 \%, 72 \%$ and $71 \%$ of pixels had over four good-quality observations in the flood/transplanting phase (Fig. 4k), even though there were no blank observations in all the above four epochs. Data availability was worst in the early 1990s' epoch when $20 \%$ of pixels were missed in the flood/transplanting phase and another $80 \%$ had only one to three instances of good observations (Fig. 4k). This indicated that potential paddy rice flooding signals could be biased in that $20 \%$ area in the epoch of the early 1990s while in the other four epochs the input data were effectively good. The statistics on the yearly scale had similar characteristics (Fig. 4l).

\subsection{Pixel- and phenology-based land cover mapping algorithms}

The pixel- and phenology-based approach has been successfully applied in mapping paddy rice using MODIS imagery in South China and South and Southeast Asia (Xiao, Boles, et al., 2005; Xiao et al., $2002,2006)$. As time series Landsat images are now available, it is important to explore whether the algorithm and Landsat data can be used in the temperate climate areas. In addition, a temperature-based phenology algorithm was added to improve selection of images at appropriate phenological stages (Table 1). Here we describe the algorithms in detail.

\subsubsection{Temperature-based plant growing season and crop calendar}

Air temperature is an important driving factor for the plant growing season, phenology and crop calendar. Usually when daily air temperatures rise above $0{ }^{\circ} \mathrm{C}$ (frost point) in the spring, natural vegetation starts to green up. Agronomical activities are typically conducted when air temperature reaches certain thresholds (Xiao, Gilbert, Slingenbergh, Lei, \& Boles, 2007), as thermal resources are one of the critical components for crop growth and crops need certain accumulated temperatures to finish their lifecycle. Therefore, delineation of thermal growing seasons for natural vegetation and crops could help us select images at appropriate time windows for better discrimination of various land cover types.

There is no universal method for defining the thermal growing seasons of different vegetation types (Linderholm, 2006). As the daily temperature variation is obvious in the study area with high latitudes, frost status is determined by daily minimum temperature. Thus, we used the daily minimum temperature thresholds of 0,5 and $10{ }^{\circ} \mathrm{C}$ (Linderholm, Walther, \& Chen, 2008) to define the phenology timing: 

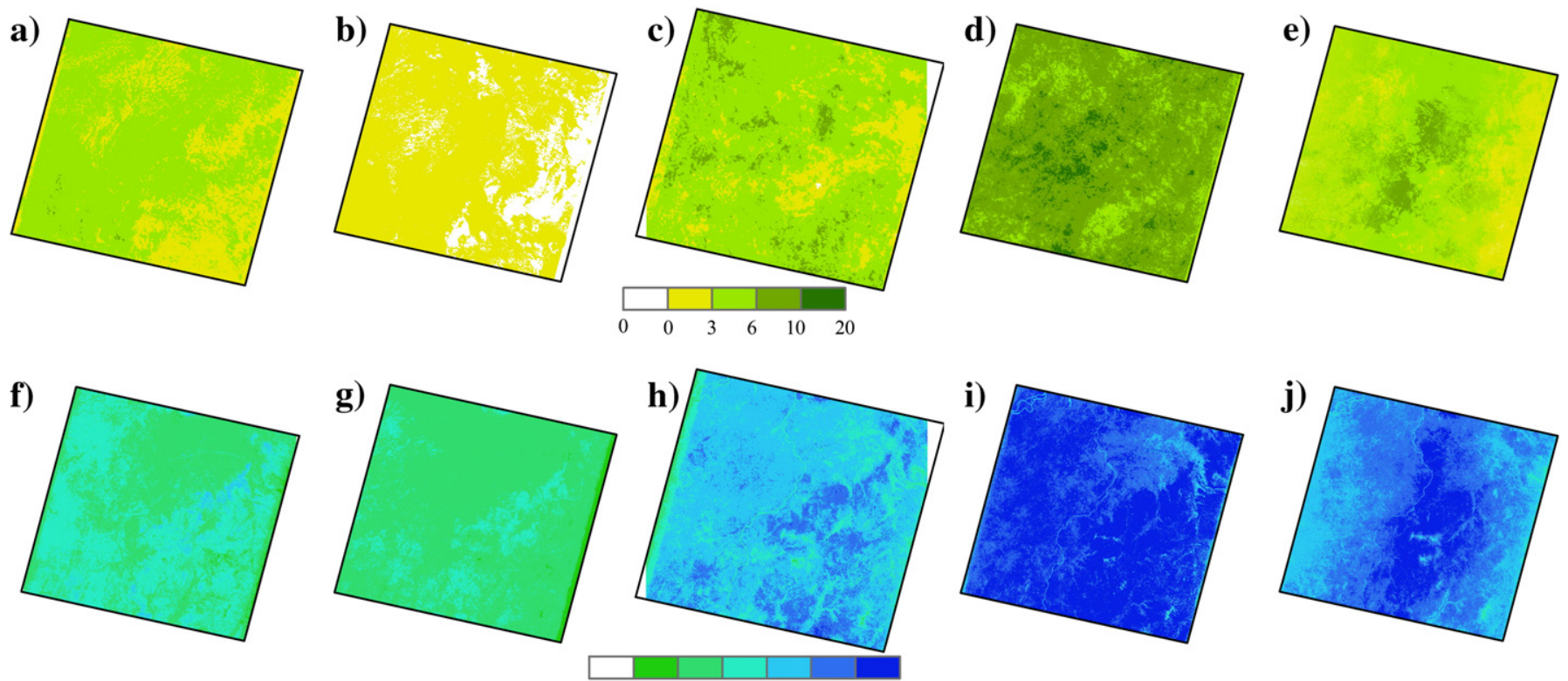

k)

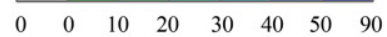

l)
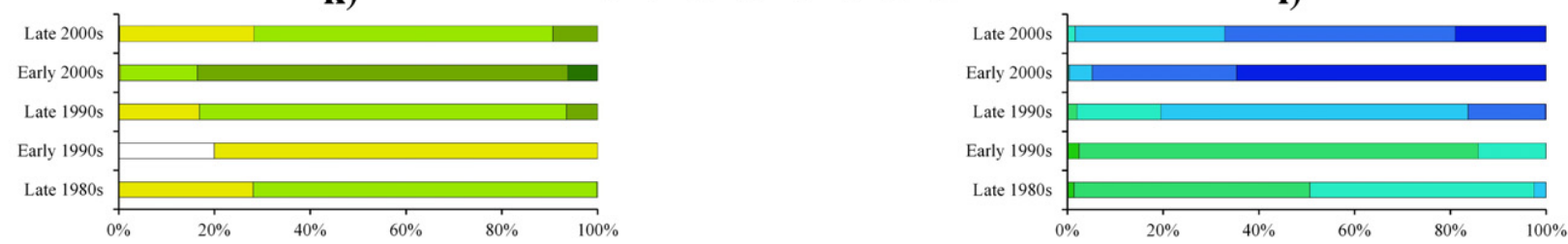

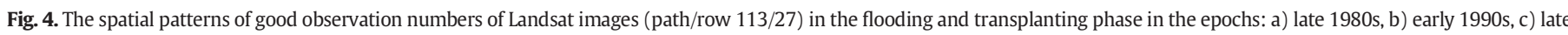

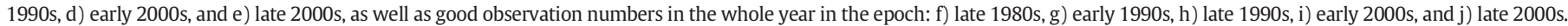
Summarized good observation statistics for e) the flooding and transplanting phase and f) the whole year.

(1) the start (TGS-0-S) and end (TGS-0-E) dates of thermal growing season above $0{ }^{\circ} \mathrm{C}$ (TGS-0), which are consistent with the last spring frost and first autumn frost and the theoretical growing season of natural vegetation; (2) the start (TGS-5-S) and end (TGS-5-E) dates of thermal growing season above $5{ }^{\circ} \mathrm{C}$ (TGS-5), which is another widelyused indicator for the theoretical growing season of vegetation; and (3) the start (TGS-10-S) and end (TGS-10-E) dates of thermal growing season above $10{ }^{\circ} \mathrm{C}$ (TGS-10), which correspond to the start and the end dates of the theoretical growing season of thermophilic crops such as paddy rice (Fig. 5). We collected daily meteorological data during 1986-2010 from the Fujin station (66.4 m asl), which is closest to the study area. Using the method described in our previous studies (Dong et al., 2009, 2013), the results of the TGS-0-S, TGS-5-S, TGS-10S, TGS-10-E, TGS-5-E, and TGS-0-E were $103 \pm 5$ (mean \pm standard deviation, SD), $123 \pm 7,144 \pm 6,256 \pm 6,275 \pm 6$, and $291 \pm$ 6 DOY, respectively. We used these thermal growing season variables to determine phenology timing of paddy rice flooding and other land cover types (Table 1). The climatic warming effects on the phenology timing during the study period (from 1986 to 2010) were limited (Fig. S3) and we used the mean - SD as the starts of growing season and mean + SD as the ends of growing season, for example, we used 138 (144 minus 6) DOY as the TGS-10-S for the algorithm (Table 1).

\subsubsection{Maps of non-cropland land cover types as masks in the algorithm}

We generated a few masks of non-cropland land cover types to reduce commission error of the resultant paddy rice maps. Here we describe these masks in brief (Table 1).

Table 1

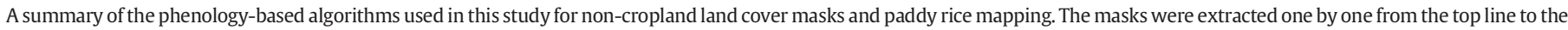

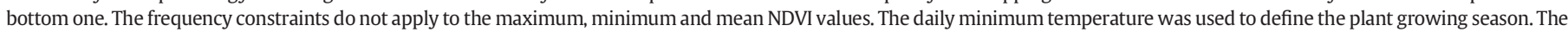
phenological dates of TGS-0-S, TGS-5-S, TGS-10-S, TGS-10-E, TGS-5-E and TGS-0-E are addressed in Section 2.3.1.

\begin{tabular}{|c|c|c|c|c|c|c|}
\hline Category & Land cover layers & NDVI & LSWI & $\begin{array}{l}\text { LSWI - NDVI } \\
(\mathrm{EVI})\end{array}$ & Time window applied & $\begin{array}{l}\text { Frequency } \\
\text { constraints }\end{array}$ \\
\hline Impervious land surface and barren lands & Built-up, barren land & & $<0$ & & TGS-5-S to TGS-5-E & $>90 \%$ \\
\hline \multirow{3}{*}{ Upland natural vegetation types } & Evergreen vegetation & & $>0$ & & DOY 1 to DOY 365 (or 366 ) & $>90 \%$ \\
\hline & Deciduous natural vegetation & $\mathrm{NDVI}_{\max }>0.5$ & & & TGS-0-S to TGS-10-S & Not applied \\
\hline & Sparse vegetation & $\mathrm{NDVI}_{\max }<0.4$ & & & TGS-0-S to TGS-0-E & Not applied \\
\hline \multirow[t]{5}{*}{ Water-related land cover types } & Permanent water body & $\mathrm{NDVI}_{\text {mean }}<0.1$ & & $>0$ & TGS-0-S to TGS-0-E & $>80 \%$ \\
\hline & Permanent mixed water/vegetation pixels & $\mathrm{NDVI}_{\text {mean }}>0.1$ & & $>0$ & TGS-5-S to TGS-5-E & $>80 \%$ \\
\hline & Spring flooded natural wetlands & $\mathrm{NDVI}_{\max }>0.3$ & & $>0$ & TGS-0-S to TGS-10-S & $>10 \%$ \\
\hline & Summer flooded natural lands & & & $>0$ & TGS- $10-\mathrm{S}+40$ to TGS-10-E & $>10 \%$ \\
\hline & Paddy rice & & & $>0$ & TGS-10-S to TGS-10-S + 40 & $>10 \%$ \\
\hline
\end{tabular}




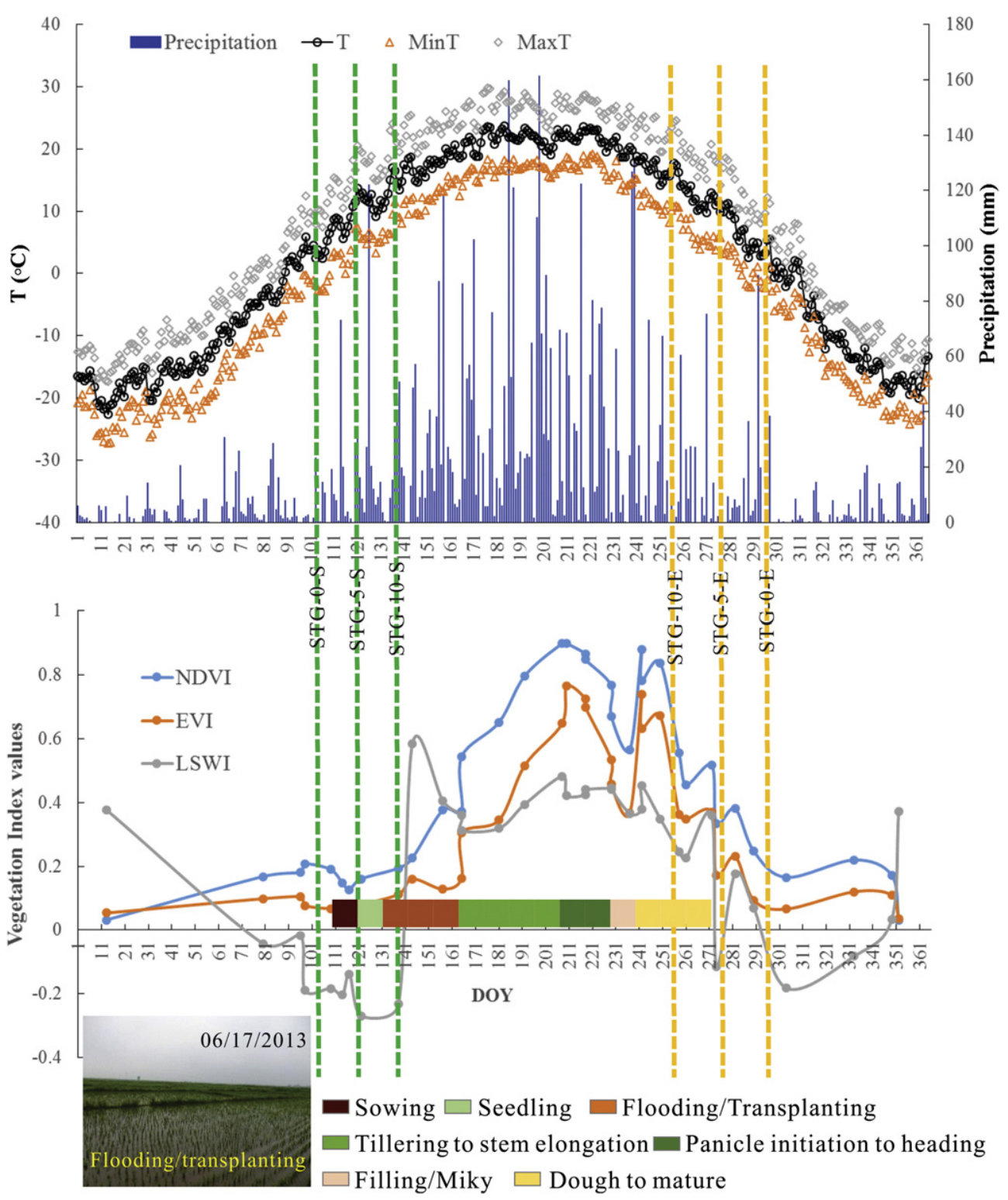

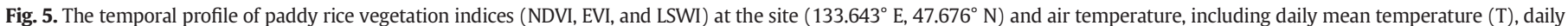

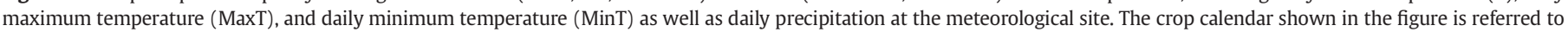

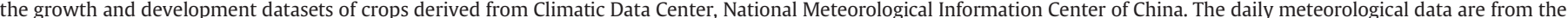

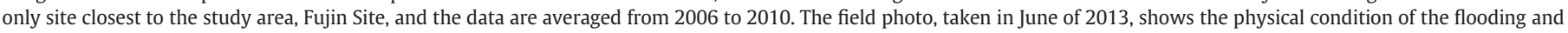
transplanting phase. The six temperature-based thermal growing season variables (TGS-0-S, TGS-5-S, TGS-10-S, TGS-0-E, TGS-5-E and TGS-10-E) are marked.

2.3.2.1. Barren land and built-up land. Built-up materials and barren land have high reflectance in the visible and higher reflectance in the shortwave infrared bands. They have $\mathrm{LSWI}<0$ values throughout the plant growing season (Fig. 6). We counted the number of observations with LSWI $<0$ within the thermal growing season above $5{ }^{\circ} \mathrm{C}$ (from TGS-5-S to TGS-5-E) and divided it by the total number of goodquality observations in a pixel, i.e., frequency of observations with LSWI $<0$. The pixels with a frequency of $>90 \%$ ( $10 \%$ error assumption) were classified as built-up and barren land (Table 1).

The frequency of a feature in all of the good observations for a pixel over an epoch period was calculated using the following equation:

$F=\frac{N_{\text {class }}}{N_{\text {total }}+N_{\text {bad }}}$

where $F_{\text {class }}$ is the frequency of a feature among all of the good-quality observations in an epoch; $N_{\text {class }}$ is the number of feature observations; $N_{\text {total }}$ is the total observation (image) number in the epoch; and $N_{b a d}$ is the number of bad observations (e.g., clouds, shadows, snow, and SLC-off gaps).

2.3.2.2. Evergreen vegetation, deciduous natural vegetation, and sparse vegetation. Evergreen vegetation has green leaves all year round, while deciduous vegetation has a period of defoliation. LSWI has proven effective in separating evergreen and deciduous vegetation in previous studies (Xiao, Boles, et al., 2005; Xiao, Biradar, Czarnecki, Alabi, \& Keller, 2009). We used the algorithm of LSWI $>0$ with a frequency of $>90 \%$ to map evergreen vegetation (e.g., trees and shrubs). After evergreen vegetation was excluded, deciduous natural vegetation can be identified through NDVI values higher than that of agricultural land in early spring. By TGS-10-S, natural vegetation has grown a few weeks after thaw and all of the new leaves have emerged; thus, it has high EVI and NDVI values (close to dense vegetation) while paddy rice or other crops are just sowed. Thus, we used the maximum NDVI $>0.5$ within the time period of TGS-0-S to TGS-10-S to generate a map of deciduous natural vegetation (Table 1 ). Besides the evergreen and 

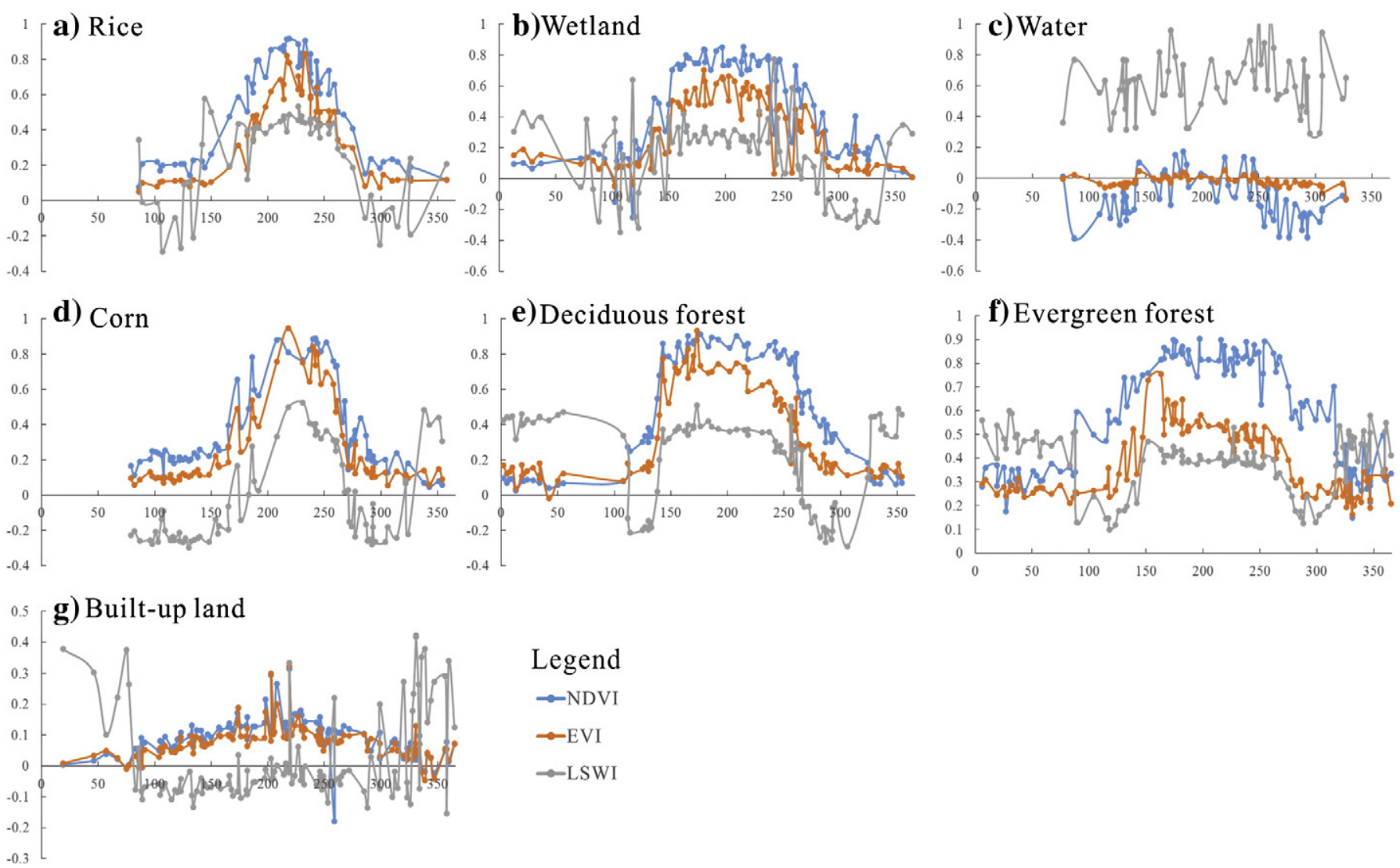

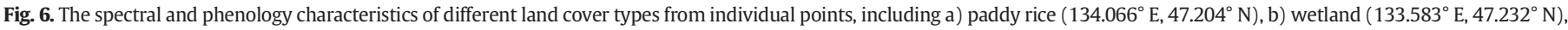

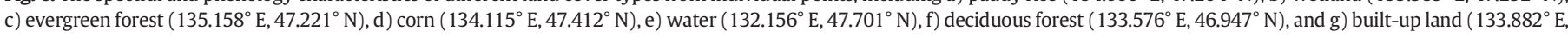
$\left.47.595^{\circ} \mathrm{N}\right)$.

deciduous vegetation (e.g., forests, shrubs, and grass), there are some areas of sparse vegetation (e.g., saline and alkaline land) distributed throughout the study area. Those sparse vegetation areas have very low greenness during the entire growing season. We used the maximum NDVI $<0.4$ in the thermal growing season above $0{ }^{\circ} \mathrm{C}$ to mask them (Table 1).

2.3.2.3. Permanent water body and mixed pixels of water and vegetation. Permanent water body and mixed pixels of water and vegetation have a unique relationship between LSWI and NDVI (EVI), i.e., LSWI > NDVI, LSWI > EVI (Xiao et al., 2002), as shown in Fig. 6. A permanent water body has lower greenness while the mixed pixels of water and vegetation have higher greenness. In this study, we used NDVI $<0.1$ at $>80 \%$ frequency within the thermal growing season above $0{ }^{\circ} \mathrm{C}$ (TGS0 -S to TGS-0-E) to map permanent water body, while we used NDVI > 0.1 at $>80 \%$ frequency to map permanent mixed pixels of water and vegetation in an epoch (Table 1 ).

2.3.2.4. Spring flooded natural wetlands and summer flooded lands. Natural wetlands are often flooded in late spring due to snowmelt, during which period natural wetlands grow rapidly and could reach NDVI values greater than 0.3 while crops are not yet planted (Fig. 6). In this study, the spring flooded natural wetlands were identified based on their flooding feature and higher NDVI values between TGS-0-S and TGS-10-S (Table 1). Besides spring snowmelt, summer precipitation also can cause some areas along rivers and streams to be flooded. Due to frequent flooding, these areas are typically retained as natural wetlands or other non-cropland land cover types. We generated these summer flooded lands according to their flooding signals in peak growing season (Table 1 ).

\subsubsection{Paddy rice}

Paddy rice has a unique agronomic feature in that it is transplanted in a mixture of soil and water, and the flood/open-canopy phase often lasts a few weeks after transplanting (Le Toan et al., 1997; Xiao et al., 2002), while other crops (e.g., wheat, corn, and soybean) do not need transplanting and are not grown in flooded soils. Before canopy closure, paddy rice fields are a mixture of water and rice plants, as observed by sensors or, in other words, "flood/open-canopy phase". After the rice canopy is closed, optical sensors cannot see water under the canopy. From the canopy closure to the ripening stages and harvest, they have similar spectral characteristics with other crops (e.g., wheat). Therefore, the key is to detect the mixed condition of surface water and green rice vegetation during the flood/open-canopy phases. As shown in Fig. 5, LSWI and EVI (or NDVI) are temporarily inversed in the flood/open-canopy phase, which has been presented in the previous studies (Xiao, Boles, et al., 2005; Xiao et al., 2002, 2006). The flood/open-canopy status was identified if an observation met the criterion of LSWI > NDVI or LSWI > EVI in the pixel. Otherwise, it was not a flood/open-canopy pixel.

Farmers do not irrigate or flood the fields until the air temperature reaches a threshold. The TGS-10-S is the starting date for paddy rice planting preparation. The flooding phase ends when the canopy closure reaches a certain level, as reflected in a quick increase in NDVI and EVI and decrease in LSWI, which typically happens 40 days after TGS-10-S. We set TGS-10-S + 40 days as the ending date for the flooding and transplanting process, when the EVI is close to 0.3-0.4 (Fig. 5). This threshold of ending date was also verified by communications with the local farmers. Thus, the potential paddy rice flooding was mapped with the phenology timing from TGS-10-S to TGS-10-S + 40 (Table 1). All of the above-mentioned non-cropland land cover masks were excluded from this map, which finally resulted in the paddy rice map in each epoch. 


\subsection{Accuracy assessment of Landsat-based paddy rice maps}

We collected the validation data from multiple sources for the five epochs of paddy rice maps. For the late 2000s, we digitized the validation areas of interest (AOIs) by integrating high resolution images and field photos. The high-resolution images in 2006-2010 used included 38 scenes of high resolution images (mainly WorldView pan images) from the National Geospatial-Intelligence Agency (NGA) Commercial Archive Data and the historical imagery archive from Google Earth, which are shown in Fig. S4. There were 846 GPS photos collected in the summer of 2013 that were managed in the Global Geo-Referenced Field Photo Library (http://www.eomf.ou.edu/photos/), and 89 plots with GPS records from 2011 were collected as well (Fig. S4). Although these field data were collected in the summers of 2013 and 2011, they can provide reference information for the AOI digitization due to the continuity of rice cropping. The AOIs were digitized according to the field shape, size and referring to the field photos (Fig. S6); not all the AOIs had associated field photos/plots due to the spatial inconsistency of high-resolution images and field data. The feature extraction (e.g., smaller field size, regular shape) of paddy rice fields was based on these field data. A total of 253 polygon AOIs (79,833 pixels, Fig. S5a) were created for a thorough accuracy assessment of the resultant land cover map using the confusion matrix approach, detailed information about the AOI numbers for different categories was shown in Table 2. For the early 2000s and late 1990s' epochs, the AOIs were digitized referring to $15-\mathrm{m}$ ETM + panchromatic layers and $30-\mathrm{m}$ color composite images from multiple growth stages by independent researchers. The color composites $(\mathrm{R} / \mathrm{G} / \mathrm{B}=$ Band 5/4/3) in the flooding and transplanting phase had remarkable features of paddy rice in tone (dark blue), regular shape and field size (Fig. S5f). Finally, we collected 76 AOIs $(37,744$ pixels) for the early 2000s and 77 AOIs $(26,778)$ for the late 1990s (Table 2). For the early 1990s and late 1980s' epochs, the AOIs were also digitized using color composite images from Landsat TM5. We also collected a land cover thematic map for 1985 as complementary reference for the late 1980s' epoch (Research Group of the Agricultural Natural Resources Survey for Sanjiang Plain, 1985). Finally, 72 AOIs (17,925 pixels) and 83 AOIs (33,961 pixels) were collected for the early 1990s and late 1980s, respectively (Table 2 ).

The AOIs in all five epochs were distributed across the study area within a stratification of four classes (paddy rice, upland crops, forest, and water/wetland) (Fig. S5a-e). Because paddy rice is the major concern of this study, we did not evaluate the other land cover types in the resultant confusion matrixes. The other three types of AOIs were combined as the non-paddy rice category.

\subsection{Inter-comparison between Landsat-RICE map and existing land cover data}

The Landsat-based paddy rice map in this study was compared with the NLCD dataset (Liu et al., 2005, 2014), which was derived from the Resource and Environment Data Center, Chinese Academy of Sciences. The NLCD-China datasets at the scale of 1:100,000 were developed through visual interpretation mainly using the Landsat TM/ETM + images (Fig. S7) (Liu et al., 2005, 2014) and included five epochs (late 1980s, 1990, 2000, 2005, and 2010). The NLCD project used a land cover classification system that has six primary land cover categories and 25 subcategories (Liu et al., 2005). Cropland categories included "paddy cropland" (paddy rice) and "dry cropland" (upland crops) categories. The overall accuracies for five epochs of primary land cover datasets were all over $91 \%$ at the national scale (Liu, Liu, Zhuang, Zhang, \& Deng, 2003; Liu et al., 2014). The vector maps were converted into $1 \mathrm{~km} \times 1 \mathrm{~km}$ gridded raster data and each grid included area fraction information for each land cover category (Liu et al., 2005). We compared the paddy rice area changes based on this gridded raster data in the five epochs. We also obtained the vector data of NLCD for two counties (Fuyuan and Raohe) in 2000, 2005 and 2010, which were converted into $30-\mathrm{m}$ raster to compare with our Landsat-RICE results for the epochs of the late 1990s, early 2000s, and late 2000s, respectively.

\section{Results}

3.1. Paddy rice planting area maps from analysis of Landsat images in the late $2000 \mathrm{~s}$

The paddy rice planting area extraction in the late 2000s' epoch was used to showcase the generation of the non-cropland masks and resultant paddy rice map (Fig. S8). In the late 2000s, most of paddy rice fields were concentrated in the plain area between the Naoli River and Heilongjiang River where water resources were rich and close to several tributaries and streams of the Heilongjiang and Wusuli Rivers. Further statements about the paddy rice maps in other epochs are detailed in the paddy rice area dynamic analysis in Section 3.4. The remaining areas that were neither paddy rice (Fig. S8b) nor noncropland masks (Fig. S8a) were unclassified, and most of those areas were upland crops, such as corn and soybean.

\subsection{Accuracy assessment of the Landsat-RICE paddy rice maps}

Accuracy assessments of the resultant paddy rice maps in five epochs were conducted by using the validation AOIs described in Section 2.4, and the results indicated that the resultant paddy rice and non-paddy rice maps had high accuracies (Table 3 ). The overall accuracies were $95 \%, 92 \%, 90 \%, 84 \%$ and $87 \%$ in the late 2000 s, early 2000s, late 1990s, early 1990s, and late 1980s' epochs, respectively, while the Kappa coefficients were $0.90,0.82,0.79,0.60$, and 0.72 respectively. The paddy rice had higher producer accuracy (PA, 94\%) and user accuracy (UA, 93\%) in the epochs of the late 2000s and early 2000s (PA 91\% and UA 97\%) due to the higher Landsat data intensity, followed by the epochs of the late 1990s and late 1980s (Table 3). The early 1990s had the lowest PA (61\%) and UA (83\%) due to data availability (Fig. 4); the limited number of good observations yielded a relatively high omission error (39\%) in the map. All of the five epochs of paddy rice maps had reasonably good accuracies and can be used to quantify the dynamics of paddy rice areas in the five epochs from 1986 to 2010. This study also indicates that the paddy rice maps from our LandsatRICE system are reliable if there are sufficient numbers of good quality observations of Landsat images.

Table 2

The areas of interest (AOIs) collected for the validations of paddy rice maps in five epochs. The numbers inside the brackets are the validation pixels used.

\begin{tabular}{|c|c|c|c|c|c|}
\hline \multirow[t]{2}{*}{ Epochs } & \multirow[t]{2}{*}{ Paddy rice } & \multicolumn{3}{|c|}{ Non-paddy rice } & \multirow[t]{2}{*}{ Total } \\
\hline & & Upland crop & Natural forests & Water/wetland & \\
\hline Late $2000 \mathrm{~s}$ & $117(26,390)$ & $44(2425)$ & $37(36,130)$ & $55(14,888)$ & $253(79,833)$ \\
\hline Early 2000 s & $28(24,871)$ & $25(4804)$ & $14(5214)$ & $9(2855)$ & $76(37,744)$ \\
\hline Late 1990 s & $26(16,164)$ & 25 (2059) & $14(5216)$ & 12 (3339) & $77(26,778)$ \\
\hline Early 1990 s & $23(5574)$ & $25(4192)$ & $13(4431)$ & $11(3728)$ & $72(17,925)$ \\
\hline Late 1980 s & $34(13,376)$ & $25(10,588)$ & $13(4681)$ & $11(5316)$ & $83(33,961)$ \\
\hline
\end{tabular}


Table 3

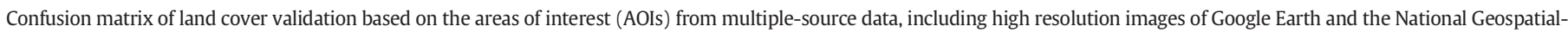

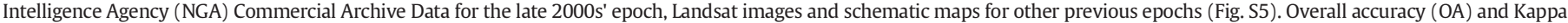
coefficients as well as user and producer accuracies are provided.

\begin{tabular}{|c|c|c|c|c|c|c|}
\hline \multirow[t]{2}{*}{ Epoch } & & & \multicolumn{2}{|c|}{$\begin{array}{l}\text { Ground truth pixels in } \\
\text { individual epochs }\end{array}$} & \multirow[t]{2}{*}{ Classified pixels } & \multirow[t]{2}{*}{ User accuracy } \\
\hline & & & Rice & Non-rice & & \\
\hline \multirow[t]{4}{*}{ Late 2000s } & Classified results & Rice & 24,698 & 1947 & 26,645 & $93 \%$ \\
\hline & & Non-rice & 1692 & 51,496 & 53,188 & $97 \%$ \\
\hline & Ground truth pixels & & 26,390 & 53,443 & 79,833 & $\mathrm{OA}=95 \%$ \\
\hline & Producer accuracy & & $94 \%$ & $96 \%$ & & Карра $=0.90$ \\
\hline \multirow[t]{4}{*}{ Early 2000s } & Classified results & Rice & 22,633 & 820 & 23,453 & $97 \%$ \\
\hline & & Non-rice & 2238 & 12,053 & 14,291 & $84 \%$ \\
\hline & Ground truth pixels & & 24,871 & 12,873 & 37,744 & $\mathrm{OA}=92 \%$ \\
\hline & Producer accuracy & & $91 \%$ & $94 \%$ & & Карра $=0.82$ \\
\hline \multirow[t]{4}{*}{ Late 1990s } & Classified results & Rice & 13,803 & 432 & 14,235 & $97 \%$ \\
\hline & & Non-rice & 2361 & 10,182 & 12,543 & $81 \%$ \\
\hline & Ground truth pixels & & 16,164 & 10,614 & 26,778 & $\mathrm{OA}=90 \%$ \\
\hline & Producer accuracy & & $85 \%$ & $96 \%$ & & Карра $=0.79$ \\
\hline \multirow[t]{4}{*}{ Early 1990 s } & Classified results & Rice & 3403 & 701 & 4104 & $83 \%$ \\
\hline & & Non-rice & 2171 & 11,650 & 13,821 & $84 \%$ \\
\hline & Ground truth pixels & & 5574 & 12,351 & 17,925 & $\mathrm{OA}=84 \%$ \\
\hline & Producer accuracy & & $61 \%$ & $94 \%$ & & Карра $=0.60$ \\
\hline \multirow[t]{4}{*}{ Late 1980 s } & Classified results & Rice & 10,522 & 1616 & 12,138 & $87 \%$ \\
\hline & & Non-rice & 2854 & 18,969 & 21,823 & $87 \%$ \\
\hline & Ground truth pixels & & 13,376 & 20,585 & 33,961 & $\mathrm{OA}=87 \%$ \\
\hline & Producer accuracy & & $79 \%$ & $92 \%$ & & Карра $=0.72$ \\
\hline
\end{tabular}

\subsection{A comparison of the Landsat-RICE maps with the NLCD datasets}

The comparisons of the Landsat-RICE maps and NLCD derived paddy rice maps in three epochs (late 2000s, early 2000s, and late 1990s) show that the two maps have higher agreement in the late 2000s' epoch (Fig. 7a), while in the other two epochs, Landsat-RICE had remarkably higher area estimates of paddy rice fields than did NLCD (Fig. 7b \& c). The zoom-in analysis in one case region shows that NLCD missed abundant paddy rice fields in the early 2000s' epoch, despite a good interpretation in cropland (Fig. 7d-f), and that similar underestimations also occurred for the late 1990s (Fig. 7c). As NLCD used the images in peak growing season to do image interpretation, different crops (e.g., paddy rice, corn, and soybean) were difficult to separate from each other spectrally (Fig. S7). The difference of the two products may also be partly attributed to the inconsistent epoch composite years of the two datasets. We used the first and second five years of each decade as the epochs, while NLCD used arbitrary and inconsistent periods (late 1980s: 1987-1989; 1995: 1995-1996; 2000: 2000; 2005: 2005; 2010: 2009-2010). Additional discussion is given in Section 4.3. We also used the same validation samples to assess the NLCD maps in the three epochs and their accuracies were lower than the Landsat-RICE's (Table S1); in particular, the NLCD's low producer accuracy and high omission error suggest that abundant rice fields were missed and classified as upland crops in NLCD maps (also shown in Fig. 7).

\subsection{Dynamics of paddy rice planting area from 1986 to 2010 as estimated by Landsat-RICE}

The paddy rice planting area in the study area expanded continuously from 1986 to 2010 (Fig. 8). In the late 1980s, paddy rice fields comprised of very limited areas $\left(154 \mathrm{~km}^{2}\right.$ in total) that were distributed in a scattered manner on the plain to the west of Wusuli River and the valley plain along the Naoli River. There was little change in the area of paddy rice through the early 1990s' epoch (with an area of $136 \mathrm{~km}^{2}$ ). However, significant increases of paddy rice fields have occurred since the 1990s, and the paddy rice area reached $727 \mathrm{~km}^{2}$ in the late $1990 \mathrm{~s}$ (Fig. 8a-e). The paddy rice expansion first occurred in the northern part of Raohe County along the Naoli River in the late 1990s, expanded north, and then the paddy rice field increased rapidly in the 2000s in Fuyuan County (Fig. 8d-e). The paddy rice expansion could be attributed to the accessibility of the river water resources. The paddy rice area reached $1460 \mathrm{~km}^{2}$ and $2900 \mathrm{~km}^{2}$ in the early 2000s and late 2000s, respectively. Both Landsat-RICE and NLCD maps showed a continuous and consistently increasing trend in the five epochs, though Landsat-RICE had higher area estimates in almost all of the epochs (Fig. 8f).

The maps of the first periods of paddy rice cultivation as well as the cultivation times were generated by overlaying the paddy rice maps from all of the epochs (Fig. 9a \& b). The paddy rice area increases (Fig. 8f) and the cultivation times (Fig. 9b inset) were consistent; which showed the most paddy rice fields had cultivation ages of less than 20 years following continuous cultivations. This was also proved by the paddy rice expansion maps among the five epochs (Fig. 9c). Paddy rice had expanded to neighboring crop fields rapidly since the 1990s and paddy rice field abandonment was very limited (Fig. 9c). In the 1980s, there were very few crop fields that had paddy rice. In the northern areas, most paddy rice was first cultivated in the late 2000s, while in the southern areas, there were more fields reclaimed for paddy rice in the late 1990s (Fig. 9a).

\section{Discussion}

4.1. The use of all available Landsat images for the phenology-based paddy rice mapping (Landsat-RICE)

Since the release of Landsat data by USGS/EROS, Landsat has become a major data source for people to conduct time series image analysis (Wulder, Masek, Cohen, Loveland, \& Woodcock, 2012), as it provides more information at a higher spatial resolution (30-m) and longer temporal range (back to 1970s) in comparison to other optical sensors, such as MODIS, MERIS, and SPOT-VGT. However, there is no operational processing system, standard surface reflectance or data quality products for Landsat images. An effort was made to archive a Web-enabled Landsat annual, seasonal, monthly, and weekly composited mosaic products (WELD) for the top of atmosphere (TOA) reflectance, TOA brightness temperature, and TOA normalized difference vegetation index (NDVI) by using the L1T ETM + images with cloud cover of $<40 \%$ (Roy et al., 2010); these mosaic products were designed to contribute to land cover dynamics (e.g., forest dynamics) as well as geo- and bio-physical parameter retrieval (Hansen et al., 2014; Roy 


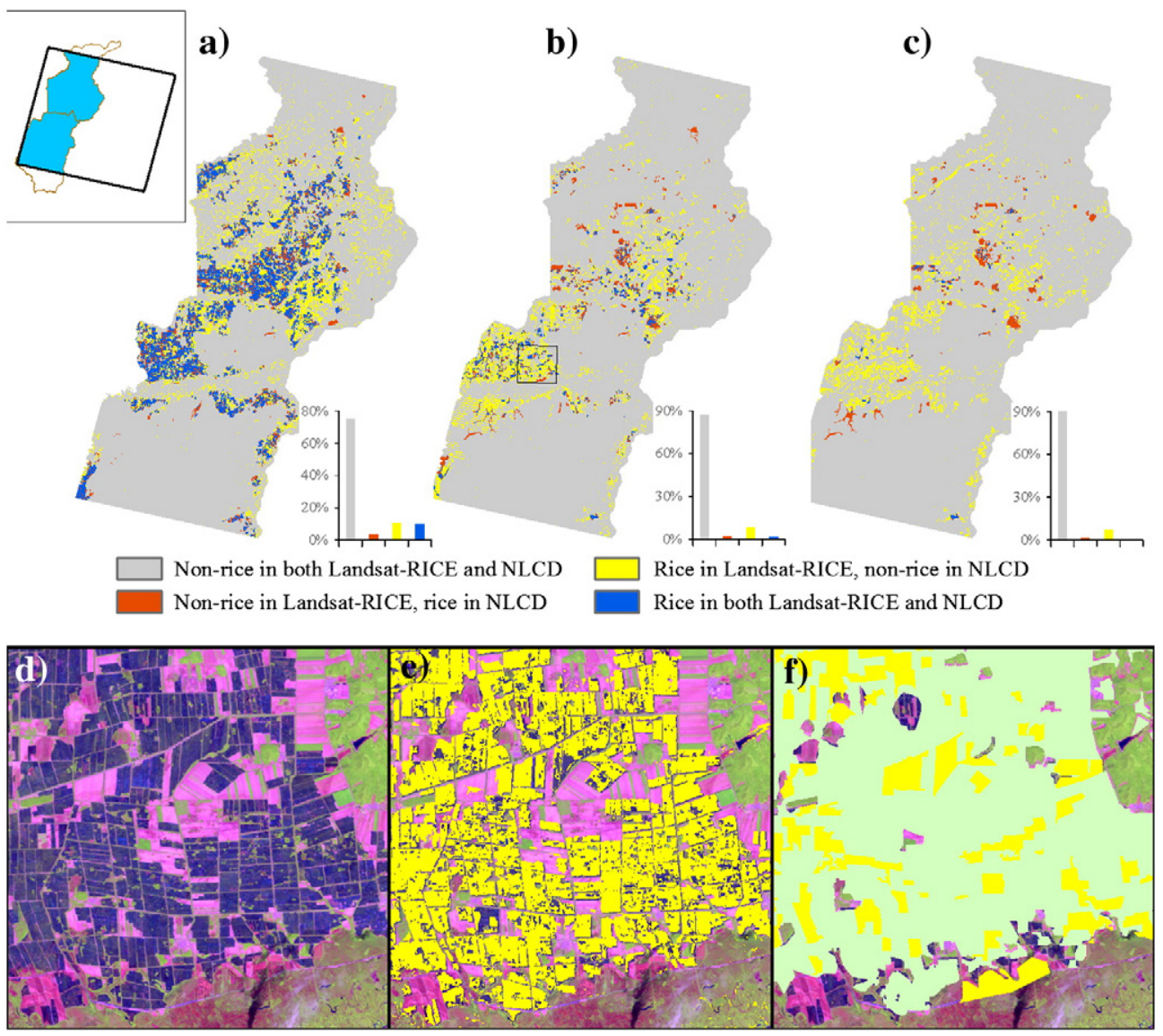

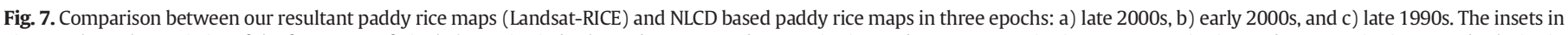

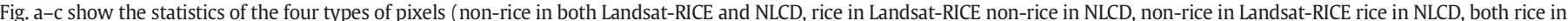

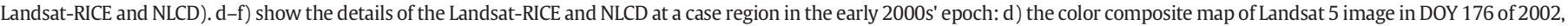
e) Landsat-RICE based rice fields (in yellow), and f) NLCD-based paddy rice fields (in yellow) and upland crops (in light green) on the background of color composite map.

et al., 2010). In this study, we offered two further improvements: first, we used all the available Landsat images in 1986-2010 from both TM and ETM + sensors, regardless of the cloud cover quantities of individual images. From a data mining perspective, the use of all available images could maximize the amount of good-quality observations for time series analysis at pixel level. Second, the surface reflectance data, instead of the TOA reflectance data, were used to improve the precision of vegetation indices.

In the Landsat-RICE system, we integrated some existing widelyused packages and algorithms to do data preprocessing, including atmospheric correction with LEDAPS (Masek et al., 2006), cloud and cloud shadow masking with Fmask (Zhu \& Woodcock, 2012), image matching with AROP (Gao et al., 2009), and snow identification (Hall et al., 1995). In addition, we developed several modules to (1) calculate vegetation indices and label the data quality information into the vegetation index products, (2) subset and stack time series images within epochs, (3) extract time series data of individual pixels (e.g., processing in Figs. 5-6), (4) analyze Landsat data availability or good-quality observation statistics (used in Figs. 3-4), and (5) map individual land cover masks through phenology-based algorithms (Table 1).

\subsection{Advantages of the pixel-and phenology-based paddy rice mapping algorithm}

Numerous studies have used individual images to generate land cover maps, based on large volumes of training datasets of various land cover types, image statistics for various spectral bands, and supervised (e.g., maximum likelihood) and/or unsupervised (e.g., K-Means) classifiers. These image- and statistics- based approaches face challenges in the extension of the resulting classifier rules and parameters over time as all of these methods are region- and phase-dependent due to the spectral variability in different periods and regions. As an alternative, time series data of individual pixels and phenology-based algorithms have been used for cropland classification, such as high temporal resolution MODIS data (Lobell \& Asner, 2004; Pan et al., 2012; Wardlow \& Egbert, 2008; Wardlow, Egbert, \& Kastens, 2007) and multi-temporal Landsat images (Zhong et al., 2014).

This study extended our previous efforts that used time series MODIS data to map paddy rice in South China and South and Southeast Asia (Xiao, Boles, et al., 2005; Xiao et al., 2006) and successfully demonstrated the consistency and robustness of the algorithms for both MODIS and Landsat images. An improvement in the algorithm is the use of the temperature-based plant-growing season to guide selection of Landsat images for various image analyses. In this study, we used the daily minimum air temperature to define plant-growing season. Our study showed that the air temperature-defined plant growing season could effectively simplify and improve the phenology-based algorithm.

\subsection{Comparison between NLCD (visual interpretation and digitalization approach) and Landsat-RICE (phenology-based automatic approach)}

Based on the same validation samples, the Landsat-RICE maps yielded a higher accuracy than that of the NLCD data derived from visual interpretation (Table S1). The accuracy of land cover maps from visual 

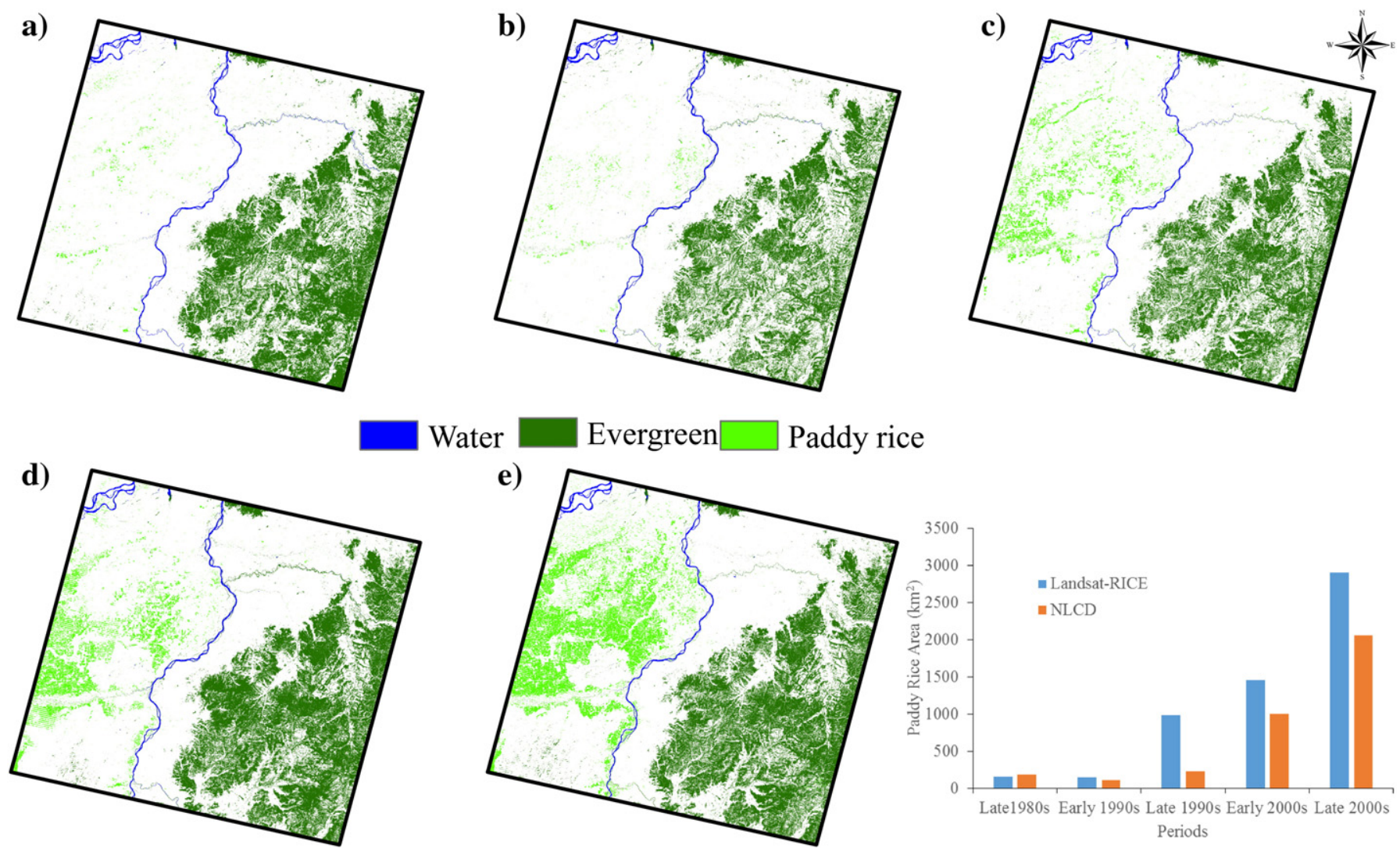

Water $\square$ Evergreen $\square$ Paddy rice
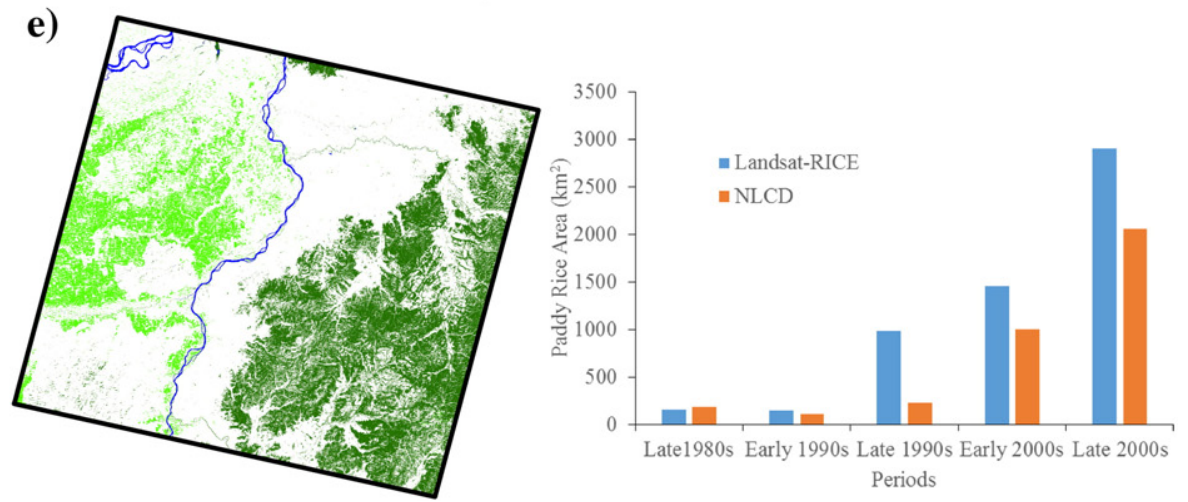

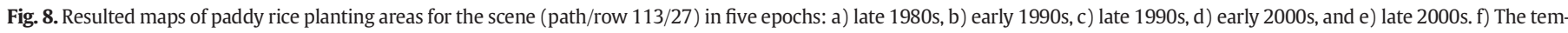
poral dynamic of paddy rice areas according to the five epochs of Landsat-RICE maps and NLCD-based paddy rice maps.

interpretation and digitalization was largely dependent on the timing of the selected images and the skills and experiences of the interpreters. Image selection in the NLCD project often used the images at peak plant growing season (Liu et al., 2005, 2014), when paddy rice, wetland, and upland crops could have similar spectral characteristics (Fig. S7). In addition, the NLCD project was labor-intensive and time-consuming. The data quality of the products over time cannot be guaranteed due to the diverse understanding of spectral features of the individual land cover types, varying experiences of interpreters, and turnover of image interpreters from the NLCD 1980s to the NLCD 2010.

Our time series Landsat- and phenology-based approach (LandsatRICE) has additional advantages. First, it can be run repeatedly in areas with similar climate and farming systems over time, independent of researchers. The algorithms are based on the understanding of phenology and the associated spectral signature of paddy rice fields. Second, the temporal Landsat-based method is likely to have more reasonable outcomes than those methods based on one image as it increases the numbers of good-quality observations in image pixels, as shown in this study.

4.4. Satellite evidence of paddy rice expansion from 1986 to 2010 and its uncertainty

Paddy rice is a major dietary staple for a billion Chinese people. Industrialization, urbanization and rural development in Southern China over the past forty years resulted in substantial loss of paddy rice and reduced cropping intensity (from triple cropping to double cropping and from double cropping to single cropping) in Southern China. This study provided satellite-based evidence of paddy rice expansion in Northeast China from 1986 to 2010, where single cropping (e.g., rice, maize and soybean) dominates. Paddy rice area increased rapidly since the late 1990 s, which was associated with increasing population pressure, paddy rice price, and climatic warming (Gao \& Liu, 2011). Our study area was located in the most northeastern part of China, which is covered by a large area of natural wetlands. The paddy rice expansion could raise many environmental problems, as the new land reclamation has reduced natural wetlands and affected terrestrial carbon cycling and biodiversity.

The ability to make quantitative comparisons of land cover maps (e.g., paddy rice area and distribution, as in this study) with different classification accuracies is a concern for remote sensing studies that use multi-decade images (e.g., Landsat) and post-classification comparison methods to quantify land cover and land use changes over time. Land cover classification accuracy is likely variable and strongly influenced by (1) availability of good-quality image data, (2) availability of in-situ data, and (3) algorithms. The implementation of the LandsatRICE system for the period from the 1980s to 2000s is largely limited by the amount of good-quality observations within the period of flooding and rice transplanting ( $\sim 1$ month in length), due to the limited number of images per year (associated with the long revisit cycle of 16 days) and variable data quality (clouds, cloud shadows, SLC-off in Landsat 7). It is difficult or impossible to generate an annual paddy rice map from a single year of Landsat images. Therefore, we combined the images in a 5-year epoch in an effort to measure changes in paddy rice area and spatial distribution at a temporal resolution of 5 years. We provided detailed analysis of data availability and quality throughout the Landsat TM/ETM + records available from USGS/EROS. The paddy rice maps for earlier epochs could still have some biases due to the data availability and quality issues which were reported by using the effective data ratios shown in the Figs. $3 c$ and 4 . The relatively high omission errors in early epochs (21\% in the late 1980s and $39 \%$ in the early 1990s) could result in an underestimation of paddy rice areas and affect the quantitative analysis of paddy rice expansion over time. More specifically, underestimation in earlier epochs could lead 
a) First epoch of paddy rice cultivation
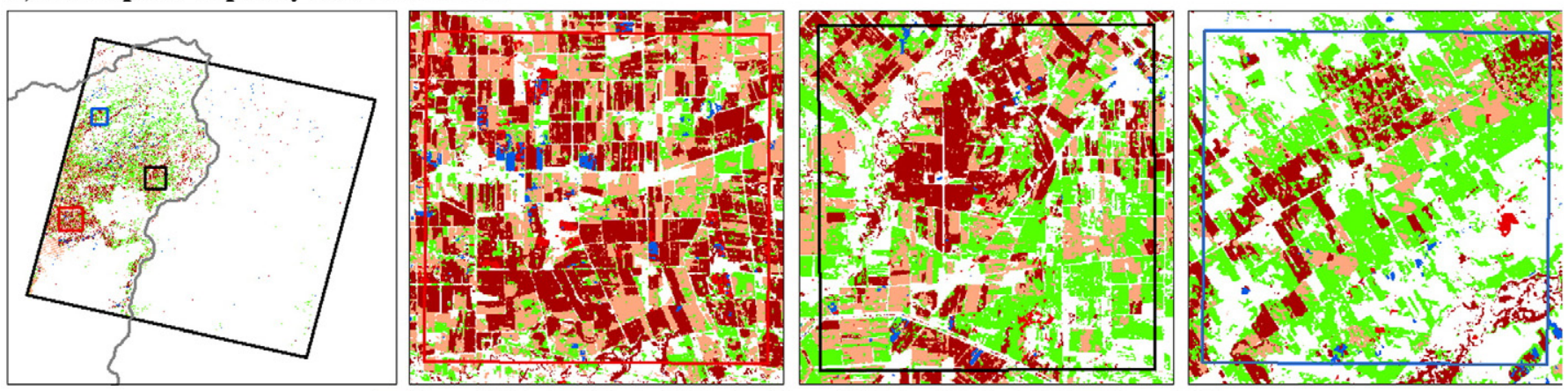

Late 1980s Early 1990s $\square$ Late 1990 s $\square$ Early $2000 \square$ Late 2000s

\section{b) Occurrence times of paddy rice cultivation}

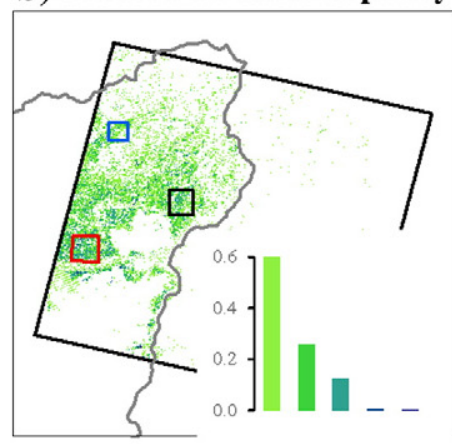

c) Paddy rice dynamics
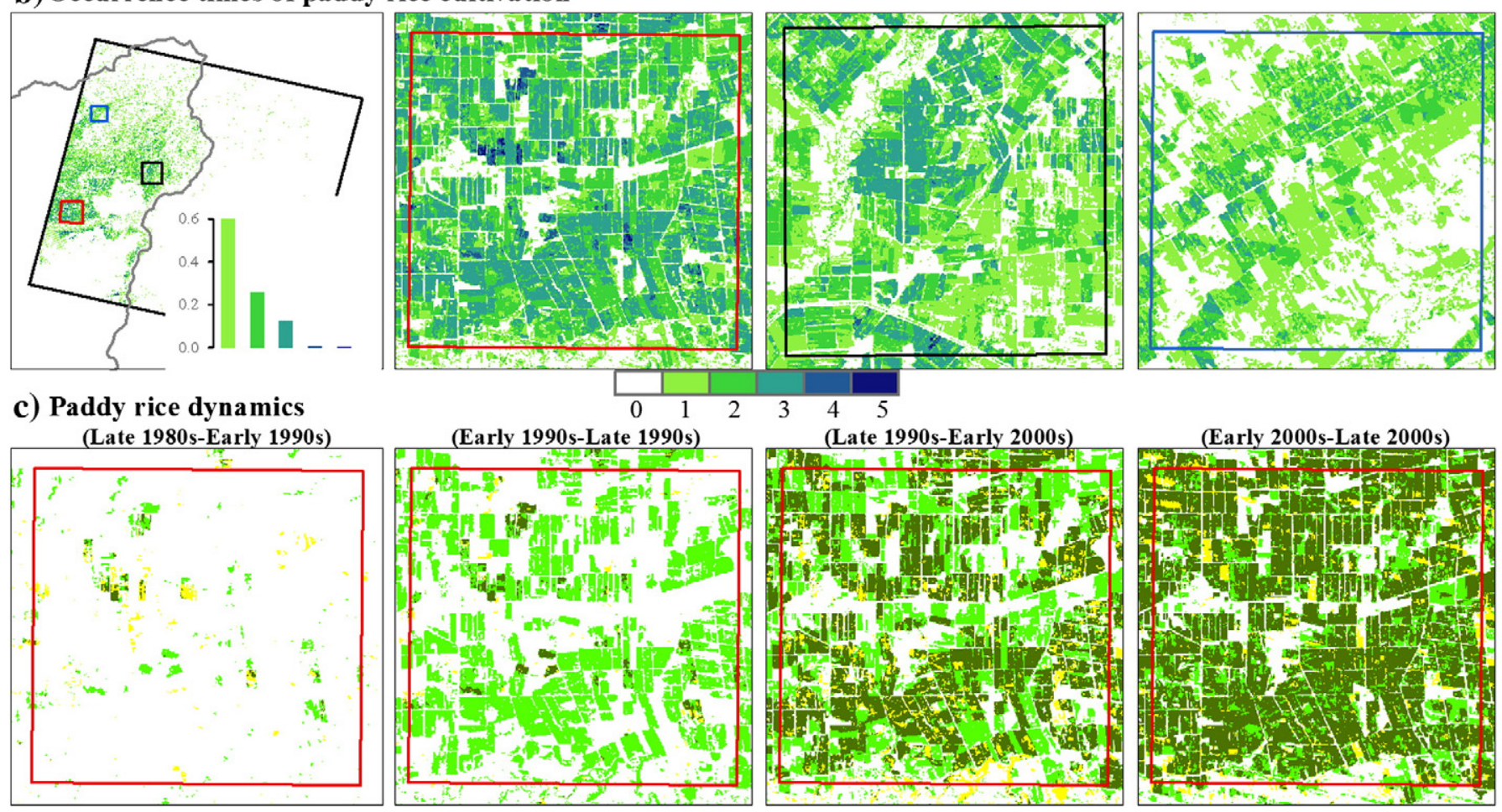

$\square$ Non-paddy rice $\square$ Rice expansion
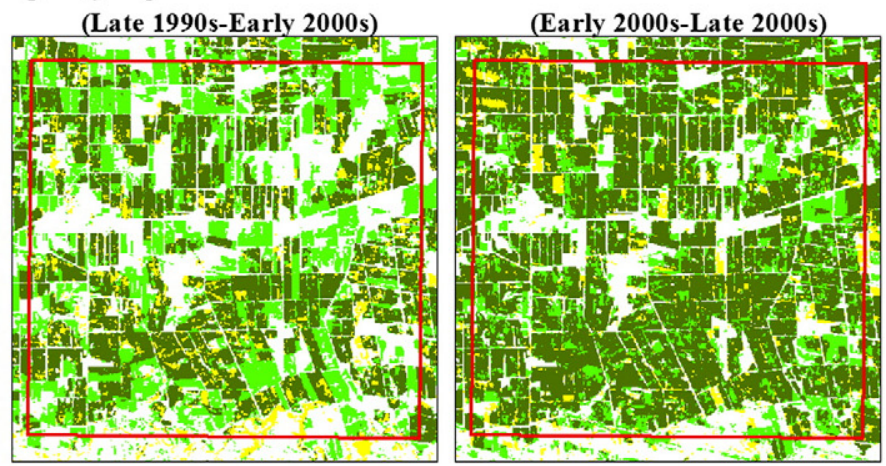

Rice abandonment $\quad$ Continuous rice

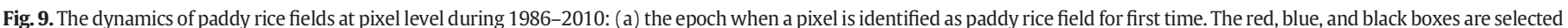

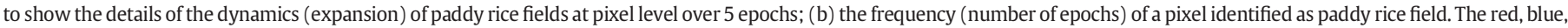

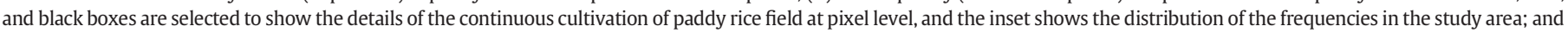
(c) the transition dynamics (inter-epoch) of paddy rice fields between two epochs. It shows one case area from the red box in (a) and (b).

to exaggerated conclusions regarding the expansion of paddy rice area. In this study, Landsat-RICE based paddy rice areas showed an increase from $136 \mathrm{~km}^{2}$ in the early 1990s to $727 \mathrm{~km}^{2}$ in the late 1990s (a 435\% increase). The $21-39 \%$ omission errors in the earlier epochs would not change the trend of paddy rice expansion qualitatively, but rather affect the magnitude estimate of expansion. Availability of in-situ data (ground reference data) over time for accuracy assessment may also affect accuracy assessment of the resultant land cover maps. In this study, the validation AOIs for the epochs of the late 1990s, early 2000s and late 2000s were derived from finer resolution imagery, including very high resolution images from NGA and Google Earth, geo-referenced photos, and/or 15-m ETM + panchromatic layers, while the validation AOIs of earlier epochs were derived from 30-m Landsat imagery and/or thematic maps collected. Further enrichment of the in-situ datasets requires the scientific communities to openly share in-situ data collected at different times for various purposes and projects. The results from this local-scale study suggest that both qualitative and quantitative comparisons of paddy rice planting area maps across various epochs with different classification accuracies are valuable. However, in order to fully form and understand quantitative comparisons between maps from different epochs with varying classification accuracies, additional studies in other regions with similar agricultural systems are critical.

\subsection{Implication and future development of paddy rice mapping}

The Landsat-RICE system may have potential to be applied to other temperate regions where there are single paddy rice croplands such as Japan and the Korea Peninsula. However, this method may not be easily extended to the tropical regions like Southern Asia where the cropping systems and land use change (e.g., deforestation) are complex (Gibbs et al., 2010) and there is also more frequent cloud coverage (Asner, 2001). There may be three strategies to overcome those challenges in tropical regions. First, we may combine more optical data sources at similar spatial resolutions, such as (1) the new planned Sentinel-2 
sensor from ESA, which could be an important compliment to Landsat (Wulder, White, Masek, Dwyer, \& Roy, 2011), (2) HJ-1-A and HJ-1-B from China, which has a multi-temporal, multispectral charge-coupled device (CCD) with setting similar to the TM/ETM + band settings (Jiang, Liang, Townshend, \& Dodson, 2013), and (3) the Indian Remote Sensing Satellite (IRS-P6) which has a medium resolution Linear Imaging Self-Scanner (LISS-III) with spatial, spectral and temporal resolutions comparable to Landsat's (Chander, Coan, \& Scaramuzza, 2008). Second, we may combine and fuse Landsat (30-m spatial resolution) and MODIS (daily temporal resolution) based on the Spatial and Temporal Adaptive Reflectance Fusion Model (STARFM) (Gao, Masek, Schwaller, \& Hall, 2006). Third, we may combine spectral and phenology information from the Landsat images with physical structure information from the synthetic aperture radar (SAR) images (Dong, Xiao, et al., 2013; Torbick et al., 2011).

\section{Conclusions}

Landsat is the only remote sensing data source to track continuous regional land use change back to the 1980 s at $30-\mathrm{m}$ spatial resolution; however, the use of time series Landsat imagery in LCLUC studies faces a series of challenges, including data quality issues (e.g., clouds, cloud shadows, and SLC-off), uneven data availability at temporal and spatial scales, incomplete datasets from various ground receiving stations, as well as relatively big data size and computation requirements. To our knowledge, this study is the first to analyze all of the available time series Landsat data in a path/row to quantify the dynamics of paddy rice planting area in northeast China. The results clearly demonstrate the value and potential for the data mining of all available time series Landsat images for long-term LCLUC studies. The Landsat-RICE system has the potential to effectively track paddy rice planting area changes in the temperate zones of northeast Asia, where there is one single cropping season and the temperature-based plant growing season can effectively simplify and improve image selection and the extraction of the rice flooding and transplanting signals. However, the extended application of the system to other regions, e.g., the subtropical and tropical regions, needs additional case studies and algorithm improvement. Future studies are needed to further develop the time series Landsat data processing system and phenology-based algorithms in an effort to improve the classification of other land cover types, which includes comprehensive study of phenology of individual land cover types and development of better phenological metrics and rules.

\section{Acknowledgments}

This study was supported by the NASA Land Use and Land Cover Change program (NNX11AJ35G), NNX14AD78G, the US National Science Foundation EPSCoR program (IIA-1301789), and the National Institutes of Health (1R01AI101028-01A1). We thank Drs. Shuwen Zhang and Wenhui Kuang for providing the NLCD vector data and Dr. Guoming Du for providing the 1985 land cover thematic map for the study area. We thank Dr. Yuchu Qin and Ms. Sarah Xiao for their comments on the earlier draft. The high resolution images were provided by NASA for use in the NASA projects with the terms of the National Geospatial-Intelligence Agency's (NGA) Nextview License Agreement.

\section{Appendix A. Supplementary data}

Supplementary data to this article can be found online at http://dx. doi.org/10.1016/j.rse.2015.01.004.

\section{References}

Arino, O., Bicheron, P., Achard, F., Latham, J., Witt, R., \& Weber, J. L. (2008). GLOBCOVER. The most detailed portrait of Earth. ESA Bulletin - European Space Agency, 24-31.
Arvidson, T., Goward, S., Gasch, J., \& Williams, D. (2006). Landsat-7 long-term acquisition plan: Development and validation. Photogrammetric Engineering and Remote Sensing, 72, 1137-1146.

Asner, G. P. (2001). Cloud cover in Landsat observations of the Brazilian Amazon. International Journal of Remote Sensing, 22, 3855-3862.

Chander, G., Coan, M. J., \& Scaramuzza, P. L. (2008). Evaluation and comparison of the IRSP6 and the Landsat sensors. IEEE Transactions on Geoscience and Remote Sensing, 46 209-221.

Cheng, Y., Wang, X., Guo, J., Zhao, Y., \& Huang, J. (2012). The temporal-spatial dynamic analysis of China rice production. Scientia Agricultura Sinica, 45, 3473-3485.

Dong, J. W., Liu, J. Y., Tao, F. L., Xu, X. L., \& Wang, J. B. (2009). Spatio-temporal changes in annual accumulated temperature in China and the effects on cropping systems, 1980 s to 2000. Climate Research, 40, 37-48.

Dong, J., Liu, J., Yan, H., Tao, F., \& Kuang, W. (2011). Spatio-temporal pattern and rationality of land reclamation and cropland abandonment in mid-eastern Inner Mongolia of China in 1990-2005. Environmental Monitoring and Assessment, 179, 137-153.

Dong, J. W., Liu, J. Y., Zhang, G. L., Basara, J. B., Greene, S., \& Xiao, X. M. (2013). Climate change affecting temperature and aridity zones: A case study in Eastern Inner Mongolia, China from 1960-2008. Theoretical and Applied Climatology, 113, 561-572.

Dong, J., Xiao, X., Chen, B., Torbick, N., Jin, C., Zhang, G., et al. (2013). Mapping deciduous rubber plantations through integration of PALSAR and multi-temporal Landsat imagery. Remote Sensing of Environment, 134, 392-402.

Dong, J. W., Xiao, X. M., Sheldon, S., Biradar, C., Duong, N. D., \& Hazarika, M. (2012). A comparison of forest cover maps in Mainland Southeast Asia from multiple sources: PALSAR, MERIS, MODIS and FRA. Remote Sensing of Environment, 127, 60-73.

Foley, J. A., DeFries, R., Asner, G. P., Barford, C., Bonan, G., Carpenter, S. R., et al. (2005) Global consequences of land use. Science, 309, 570-574.

Friedl, M. A., Mclver, D. K., Hodges, J. C. F., Zhang, X. Y., Muchoney, D., Strahler, A. H., et al (2002). Global land cover mapping from MODIS: Algorithms and early results. Remote Sensing of Environment, 83, 287-302.

Friedl, M. A., Sulla-Menashe, D., Tan, B., Schneider, A., Ramankutty, N., Sibley, A., et al. (2010). MODIS Collection 5 global land cover: Algorithm refinements and characterization of new datasets. Remote Sensing of Environment, 114, 168-182.

Fritz, S., See, L., \& Rembold, F. (2010). Comparison of global and regional land cover maps with statistical information for the agricultural domain in Africa. International Journa of Remote Sensing, 31, 2237-2256.

Gao, J., \& Liu, Y. (2011). Climate warming and land use change in Heilongjiang Province, Northeast China. Applied Geography, 31, 476-482

Gao, F., Masek, J., Schwaller, M., \& Hall, F. (2006). On the blending of the Landsat and MODIS surface reflectance: Predicting daily Landsat surface reflectance. IEEE Transactions on Geoscience and Remote Sensing, 44, 2207-2218.

Gao, F., Masek, J. G., \& Wolfe, R. E. (2009). Automated registration and orthorectification package for Landsat and Landsat-like data processing. Journal of Applied Remote Sensing, 3.

Gibbs, H. K., Ruesch, A. S., Achard, F., Clayton, M. K., Holmgren, P., Ramankutty, N., et al. (2010). Tropical forests were the primary sources of new agricultural land in the 1980s and 1990s. Proceedings of the National Academy of Sciences of the United States of America, 107, 16732-16737.

Gibson, L., Lee, T. M., Koh, L. P., Brook, B. W., Gardner, T. A., Barlow, J., et al. (2011). Primary forests are irreplaceable for sustaining tropical biodiversity. Nature, 478, 378-381.

Gong, P., Wang, J., Yu, L., Zhao, Y., Zhao, Y., Liang, L., et al. (2013). Finer resolution observation and monitoring of global land cover: First mapping results with Landsat TM and ETM + data. International Journal of Remote Sensing, 34, 2607-2654.

Goodwin, N. R., Collett, L. J., Denham, R. J., Flood, N., \& Tindall, D. (2013). Cloud and cloud shadow screening across Queensland, Australia: An automated method for Landsat TM/ETM plus time series. Remote Sensing of Environment, 134, 50-65.

Hall, D. K., Riggs, G. A., \& Salomonson, V. V. (1995). Development of methods for mapping global snow cover using moderate resolution imaging spectroradiometer data. Remote Sensing of Environment, 54, 127-140.

Hansen, M. C., Egorov, A., Potapov, P. V., Stehman, S. V., Tyukavina, A., Turubanova, S. A., et al. (2014). Monitoring conterminous United States (CONUS) land cover change with WebEnabled Landsat Data (WELD). Remote Sensing of Environment, 140, 466-484.

Hansen, M. C., Potapov, P. V., Moore, R., Hancher, M., Turubanova, S. A., Tyukavina, A., et al (2013). High-resolution global maps of 21st-century forest cover change. Science, $342,850-853$.

Huang, C., Goward, S. N., Masek, J. G., Thomas, N., Zhu, Z., \& Vogelmann, J. E. (2010). An automated approach for reconstructing recent forest disturbance history using dense Landsat time series stacks. Remote Sensing of Environment, 114, 183-198.

Huang, C. Q., Goward, S. N., Masek, J. G., Gao, F., Vermote, E. F., Thomas, N., et al. (2009) Development of time series stacks of Landsat images for reconstructing forest disturbance history. International Journal of Digital Earth, 2, 195-218.

Huete, A., Didan, K., Miura, T., Rodriguez, E. P., Gao, X., \& Ferreira, L. G. (2002). Overview of the radiometric and biophysical performance of the MODIS vegetation indices. Remote Sensing of Environment, 83, 195-213.

Huete, A. R., Liu, H. Q., Batchily, K., \& vanLeeuwen, W. (1997). A comparison of vegetation indices over a global set of TM images for EOS-MODIS. Remote Sensing of Environment, $59,440-451$.

Jiang, B., Liang, S. L., Townshend, J. R., \& Dodson, Z. M. (2013). Assessment of the radiometric performance of Chinese HJ-1 satellite CCD instruments. IEEE Journal of Selected Topics in Applied Earth Observations and Remote Sensing, 6, 840-850.

Lambin, E. F., \& Meyfroidt, P. (2011). Global land use change, economic globalization, and the looming land scarcity. Proceedings of the National Academy of Sciences of the United States of America, 108, 3465-3472.

Le Toan, T., Ribbes, F., Li-Fang, W., Floury, N., Kung-Hau, D., Jin Au, K., et al. (1997). Rice crop mapping and monitoring using ERS-1 data based on experiment and modeling results. IEEE Transactions on Geoscience and Remote Sensing, 35, 41-56. 
Linderholm, H. W. (2006). Growing season changes in the last century. Agricultural and Forest Meteorology, 137, 1-14.

Linderholm, H. W., Walther, A., \& Chen, D. L. (2008). Twentieth-century trends in the thermal growing season in the Greater Baltic Area. Climatic Change, 87, 405-419.

Lindquist, E. J., Hansen, M. C., Roy, D. P., \& Justice, C. O. (2008). The suitability of decadal image data sets for mapping tropical forest cover change in the Democratic Republic of Congo: Implications for the global land survey. International Journal of Remote Sensing, 29, 7269-7275.

Liu, J., Kuang, W., Zhang, Z., Xu, X., Qin, Y., Ning, J., et al. (2014). Spatiotemporal characteristics, patterns, and causes of land-use changes in China since the late 1980s. Journal of Geographical Sciences, 24, 195-210.

Liu, J., Liu, M., Tian, H., Zhuang, D., Zhang, Z., Zhang, W., et al. (2005). Spatial and temporal patterns of China's cropland during 1990-2000: An analysis based on Landsat TM data. Remote Sensing of Environment, 98, 442-456.

Liu, J. Y., Liu, M. L., Zhuang, D. F., Zhang, Z. X., \& Deng, X. Z. (2003). Study on spatial pattern of land-use change in China during 1995-2000. Science in China Series D - Earth Sciences, 46, 373-384.

Liu, H. Y., Zhang, S. K., Li, Z. F., Lu, X. G., \& Yang, Q. (2004). Impacts on wetlands of largescale land-use changes by agricultural development: The small Sanjiang Plain, China. Ambio, 33, 306-310.

Lobell, D. B., \& Asner, G. P. (2004). Cropland distributions from temporal unmixing of MODIS data. Remote Sensing of Environment, 93, 412-422.

Masek, J. G., Goward, S. N., Kennedy, R. E., Cohen, W. B., Moisen, G. G., Schleeweis, K., et al. (2013). United States forest disturbance trends observed using Landsat time series. Ecosystems, 16, 1087-1104.

Masek, J. G., Vermote, E. F., Saleous, N. E., Wolfe, R., Hall, F. G., Huemmrich, K. F., et al. (2006). A Landsat surface reflectance dataset for North America, 1990-2000. IEEE Geoscience and Remote Sensing Letters, 3, 68-72.

NASA Goddard Space Flight Center (2011). Landsat 7 science data users handbook. http:// landsathandbook.gsfc.nasa.gov/pdfs/Landsat7_Handbook.pdf

Pan, Y., Li, L., Zhang, J., Liang, S., Zhu, X., \& Sulla-Menashe, D. (2012). Winter wheat area estimation from MODIS-EVI time series data using the Crop Proportion Phenology Index. Remote Sensing of Environment, 119, 232-242.

Research Group of the Agricultural Natural Resources Survey for Sanjiang Plain (1985). Vegetation type map in the Sanjiang Plain. Changchun, China: Northeast Institute of Geography and Agroecology, Chinese Academy of Sciences.

Roy, D. P., Ju, J. C., Kline, K., Scaramuzza, P. L., Kovalskyy, V., Hansen, M., et al. (2010). Webenabled Landsat Data (WELD): Landsat ETM plus composited mosaics of the conterminous United States. Remote Sensing of Environment, 114, 35-49.

Simpson, J. J., Jin, Z. H., \& Stitt, J. R. (2000). Cloud shadow detection under arbitrary viewing and illumination conditions. IEEE Transactions on Geoscience and Remote Sensing, 38, 972-976.

Tao, F., Hayashi, Y., Zhang, Z., Sakamoto, T., \& Yokozawa, M. (2008). Global warming, rice production, and water use in China: Developing a probabilistic assessment. Agricultural and Forest Meteorology, 148, 94-110.

Tao, F., Yokozawa, M., Liu, J. Y., \& Zhang, Z. (2009). Climate change, land use change, and China's food security in the twenty-first century: An integrated perspective. Climatic Change, 93, 433-445.

Thenkabail, P. S. (2009). Remote sensing of global croplands for food security. Boca Raton: CRC Press.

Thenkabail, P. S., Dheeravath, V., Biradar, C. M., Gangalakunta, O. R. P., Noojipady, P., Gurappa, C., et al. (2009). Irrigated area maps and statistics of India using remote sensing and national statistics. Remote Sensing, 1, 50-67.

Thenkaball, P. S., GangadharaRao, P., Biggs, T. W., Krishna, M., \& Turral, H. (2007). Spectral matching techniques to determine historical Land-use/Land-cover (LULC) and irrigated areas using time-series 0.1-degree AVHRR pathfinder datasets. Photogrammetric Engineering and Remote Sensing, 73, 1029-1040.

Thomas, N. E., Huang, C. Q., Goward, S. N., Powell, S., Schleeweis, K., \& Hinds, A. (2011). Validation of North American Forest Disturbance dynamics derived from Landsat time series stacks. Remote Sensing of Environment, 115, 19-32.

Torbick, N., Salas, W., Xiao, X., Ingraham, P., Fearon, Matthew G., Biradar, C., et al. (2011). Integrating SAR and optical imagery for regional mapping of paddy rice attributes in the Poyang Lake Watershed, China. Canadian Journal of Remote Sensing, 37, 17-26.

Tucker, C. J. (1979). Red and photographic infrared linear combinations for monitoring vegetation. Remote Sensing of Environment, 8, 127-150.

Turner, B. L., Lambin, E. F., \& Reenberg, A. (2007). The emergence of land change science for global environmental change and sustainability. Proceedings of the National Academy of Sciences of the United States of America, 104, 20666-20671.
Vermote, E. F., ElSaleous, N., Justice, C. O., Kaufman, Y. J., Privette, J. L., Remer, L., et al. (1997). Atmospheric correction of visible to middle-infrared EOS-MODIS data over land surfaces: Background, operational algorithm and validation. Journal of Geophysical Research - Atmospheres, 102, 17131-17141.

Wang, Z. M., Song, K. S., Ma, W. H., Ren, C. Y., Zhang, B., Liu, D. W., et al. (2011). Loss and fragmentation of marshes in the Sanjiang Plain, northeast China, 1954-2005. Wetlands, 31, 945-954.

Wang, L. L., Song, C. C, Song Y. Y, Guo, Y. D. Wang X. W \& Sun, X. X. (2010). Effects of reclamation of natural wetlands to a rice paddy on dissolved carbon dynamics in the Sanjiang Plain, northeastern China. Ecological Engineering, 36, 1417-1423.

Wardlow, B. D., \& Egbert, S. L. (2008). Large-area crop mapping using time-series MODIS 250 m NDVI data: An assessment for the US Central Great Plains. Remote Sensing of Environment, 112, 1096-1116.

Wardlow, B. D., Egbert, S. L., \& Kastens, J. H. (2007). Analysis of time-series MODIS $250 \mathrm{~m}$ vegetation index data for crop classification in the US Central Great Plains. Remote Sensing of Environment, 108, 290-310.

Waser, L. T., \& Schwarz, M. (2006). Comparison of large-area land cover products with national forest inventories and CORINE land cover in the European Alps. International Journal of Applied Earth Observation and Geoinformation, 8, 196-207.

West, P. C., Gibbs, H. K., Monfreda, C., Wagner, J., Barford, C. C., Carpenter, S. R., et al. (2010). Trading carbon for food: Global comparison of carbon stocks vs. crop yields on agricultural land. Proceedings of the National Academy of Sciences of the United States of America, 107, 19645-19648.

Wu, W., Shibasaki, R., Yang, P., Zhou, Q., \& Tang, H. (2008). Remotely sensed estimation of cropland in China: A comparison of the maps derived from four global land cover datasets. Canadian Journal of Remote Sensing, 34, 467-479.

Wulder, M. A., Masek, J. G., Cohen, W. B., Loveland, T. R., \& Woodcock, C. E. (2012). Opening the archive: How free data has enabled the science and monitoring promise of Landsat. Remote Sensing of Environment, 122, 2-10.

Wulder, M. A., White, J. C., Masek, J. G., Dwyer, J., \& Roy, D. P. (2011). Continuity of Landsat observations: Short term considerations. Remote Sensing of Environment, 115, 747-751.

Xiao, X., Biradar, C., Czarnecki, C., Alabi, T., \& Keller, M. (2009). A simple algorithm for large-scale mapping of evergreen forests in tropical America, Africa and Asia. Remote Sensing, 1, 355-374.

Xiao, X. M., Boles, S., Frolking, S., Li, C. S., Babu, J. Y., Salas, W., et al. (2006). Mapping paddy rice agriculture in South and Southeast Asia using multi-temporal MODIS images. Remote Sensing of Environment, 100, 95-113.

Xiao, X., Boles, S., Frolking, S., Salas, W., Moore, B., Li, C., et al. (2002). Observation of flooding and rice transplanting of paddy rice fields at the site to landscape scales in China using VEGETATION sensor data. International Journal of Remote Sensing, 23, 3009-3022.

Xiao, X. M., Boles, S., Liu, J. Y., Zhuang, D. F., Frolking, S., Li, C. S., et al. (2005). Mapping paddy rice agriculture in southern China using multi-temporal MODIS images. Remote Sensing of Environment, 95, 480-492.

Xiao, X. M., Gilbert, M., Slingenbergh, J., Lei, F., \& Boles, S. (2007). Remote sensing, ecological variables, and wild bird migration related to outbreaks of highly pathogenic H5N1 avian influenza. Journal of Wildlife Diseases, 43, S40-S46.

Xiao, X. M., Hollinger, D., Aber, J., Goltz, M., Davidson, E. A., Zhang, Q. Y., et al. (2004). Satellite-based modeling of gross primary production in an evergreen needleleaf forest. Remote Sensing of Environment, 89, 519-534.

Xiao, X. M., Zhang, Q. Y., Hollinger, D., Aber, J., \& Moore, B. (2005). Modeling gross primary production of an evergreen needleleaf forest using MODIS and climate data. Ecological Applications, 15, 954-969.

Yang, Y. H., Yan, B. X., \& Zhu, H. (2011). Estimating soil erosion in northeast China using Cs-137 and Pb-210(ex). Pedosphere, 21, 706-711.

Zhang, S. Q., Na, X. D., Kong, B., Wang, Z. M., Jiang, H. X., Yu, H., et al. (2009). Identifying wetland change in China's Sanjiang Plain using remote sensing. Wetlands, 29, 302-313.

Zhang, Y., Wang, Y. Y., Su, S. L., \& Li, C. S. (2011). Quantifying methane emissions from rice paddies in Northeast China by integrating remote sensing mapping with a biogeochemical model. Biogeosciences, 8, 1225-1235.

Zhong, L., Gong, P., \& Biging, G. S. (2014). Efficient corn and soybean mapping with temporal extendability: A multi-year experiment using Landsat imagery. Remote Sensing of Environment, 140, 1-13.

Zhu, Z., \& Woodcock, C. E. (2012). Object-based cloud and cloud shadow detection in Landsat imagery. Remote Sensing of Environment, 118, 83-94. 